The Pleasure of Making a Difference: Perceived Social Contribution Explains the Relation Between Extraverted Behavior and Positive Affect

\author{
Jessie $\operatorname{Sun}^{1,2}$ \\ Kathryn Stevenson ${ }^{1}$ \\ Rachel Kabbani ${ }^{1}$ \\ Ben Richardson ${ }^{3}$ \\ Luke D. Smillie ${ }^{1}$
}

${ }^{1}$ Melbourne School of Psychological Sciences, The University of Melbourne, Australia

${ }^{2}$ Department of Psychology, University of California, Davis, U.S.

${ }^{3}$ School of Psychology, Deakin University, Australia

Original submission date: January 28, 2016

Revised submission date: October 30, 2016

Accepted: December 7, 2016

Address all correspondence to jesun@ucdavis.edu

Sun, J., Stevenson, K., Kabbani, R., Richardson, B., \& Smillie, L. D. (in press). The pleasure of making a difference: Perceived social contribution explains the relation between extraversion and positive affect. Emotion. 


\begin{abstract}
Why are trait extraversion and extraverted behaviors both associated with greater positive affect? Across three studies, we examined whether two aspects of social experienceperceived social contribution and social power-mediate the relation between extraversion and positive affect. Study $1(N=205)$ showed that trait measures of social contribution and power mediated the relation between trait extraversion and trait positive affect. Study $2(N=$ 78) showed that state social contribution and power helped to explain the greater levels of state positive affect reported by participants who were instructed to enact extraverted behaviors. Finally, Study $3(N=62)$ showed that social contribution and power mediated the relation between natural fluctuations in extraverted behavior and positive affect states in daily life. In all three studies, multiple-mediator models showed that social contribution, but not power, independently mediated the relations that trait and state extraversion had with positive affect. This suggests that perceptions of positive influence-more so than a general sense of power-help to explain why extraverts and extraverted moments are happier. We link these findings to emerging trends in the study of personality dynamics and the potential benefits of acting "out of character".
\end{abstract}

Key Words: Extraverted Behavior; Extraversion; Positive Affect; Social Contribution; Social Power 
The Pleasure of Making a Difference: Perceived Social Contribution Explains the Relation Between Extraverted Behavior and Positive Affect

Extraversion is one of five basic trait domains that describe the structure of personality (John, Naumann, \& Soto, 2008), and can be defined as the tendency to be talkative, assertive, and sociable at the high end of the continuum, and quiet, passive, and reserved at the opposite ("introverted") end. The tendency for extraverts to experience higher levels of positive affect (PA) is often described as one of the most robust findings in personality psychology (Lucas \& Fujita, 2000; Smillie, DeYoung, \& Hall, 2015; Steel, Schmidt, \& Shultz, 2008), and holds across several cultures (Lucas, Diener, Grob, Suh, \& Shao, 2000). This relation is strongest when PA is defined, in line with Watson and Tellegen's (1985) factor model of affect, as the combination of pleasant valence and high activation (e.g., lively, excited; see Smillie, DeYoung, \& Hall, 2015). Therefore, extraverts tend to be "happier" - a term we use as short-hand — in the sense that they experience higher levels of PA.

The extraversion-PA relation also holds at the state level: individuals feel happier in the moments in which they behave in a more talkative and sociable way. Several experimental studies have provided causal evidence that participants who are instructed to act extraverted (e.g., talkative, bold, assertive) report higher levels of PA than those instructed to act introverted (e.g., quiet, passive, reserved) during interactive activities in the lab (Gallagher, Fleeson, \& Hoyle, 2011; McNiel \& Fleeson, 2006; McNiel, Lowman, \& Fleeson, 2010; Smillie, Wilt, Kabbani, Garratt, \& Revelle, 2015; Zelenski et al., 2013; Zelenski, Santoro, \& Whelan, 2012). Experience sampling (ESM) studies, in which participants use a mobile device to report their momentary levels of extraverted behavior and PA across several time points during their daily lives, also reveal a positive relation between within-person fluctuations in extraverted behavior and PA states (Fleeson, Malanos, \& Achille, 2002; Wilt, 
Bleidorn, \& Revelle, 2016; Wilt, Noftle, Fleeson, \& Spain, 2012). Like the trait-level association, this state-level association appears to generalize across several cultures (Ching et al., 2014). In addition, perhaps surprisingly, no study has found an interaction between trait extraversion and extraverted behavior on PA, indicating that the affective benefits of acting extraverted may apply to dispositional introverts and extraverts alike.

Although many theories have attempted to explain why extraverts are happier (e.g., Gross, Sutton, \& Ketelaar, 1998; Larsen \& Ketelaar, 1989; Lucas, Le, \& Dyrenforth, 2008), very little research has been able to explain why it feels good to act like an extravert (see Smillie, 2013, for a review). Yet, recent research suggests that explaining why extraverted moments are happier could shed new light on the long-standing question of why trait extraverts are happier (Wilt et al., 2012). Through a series of ESM studies, Wilt and colleagues (2012) found support for a model in which extraverted behaviors and PA states mediate part of the relation between trait extraversion and trait PA. In other words, extraverts may be happier because of what they "do" (i.e., act extraverted more often), and not just what they "have" (see Cantor, 1990). If this model is robust, the processes that mediate the relation between extraverted behaviors and PA states may also mediate the relation between trait extraversion and trait PA. The current investigation seeks to explain the state-level relation between extraverted behavior and PA.

Recent studies suggest that positive social experiences associated with extraverted behavior may help to explain its effect on PA (Howell, Ksendzova, Nestingen, Yerahian, \& Iyer, 2016; Smillie, Wilt, et al., 2015). Extraverts have qualitatively different social experiences compared to introverts, including higher ratings of friendship quality, closeness, and satisfaction (Berry, Willingham, \& Thayer, 2000; Festa, Barry, Sherman, \& Grover, 2012; Wilson, Harris, \& Vazire, 2015), as well as deeper conversations, greater selfdisclosure, and increased shared reminiscing in daily life (McLean \& Pasupathi, 2006; 
Wilson et al., 2015). These perceptions may emerge due to the impact of extraverted behavior on social processes (Eaton \& Funder, 2003).

Motivated by such findings, Smillie, Wilt, et al. (2015) proposed that qualitative aspects of social experience- beyond mere quantity of time spent in social activities (Lucas et al., 2008) — could help to explain the relation between enacted extraversion and PA. In an initial correlational study, Smillie, Wilt, et al. (2015, Study 1) investigated whether individual differences in quality of social experience mediate the relation between trait extraversion and trait PA. Results showed that a multidimensional measure of social well-being (Keyes, 1998) explained $32 \%$ of the relation between trait extraversion and PA. Of the five subscales, social contribution (believing that one has something valuable to give, and does give, to society) was the strongest mediator, independently explaining $29 \%$ of the trait extraversion-PA relation. To bolster this correlational study with experimental evidence, Smillie, Wilt, and colleagues (Study 2) then investigated whether state measures of social well-being and social contribution mediated the relation between enacted extraversion and increased PA. As a state measure of social contribution, participants reported the percentage to which they "contributed to the discussion tasks", relative to the other two participants. Mirroring the trait-level findings, single-mediator models showed that social well-being and social contribution both helped to explain the effect of acting extraverted on PA. However, social contribution again emerged as a particularly strong mediator, explaining $70 \%$ of this effect.

Smillie, Wilt, and colleagues' (2015, Study 2) findings therefore suggest that qualitative aspects of social experience, especially perceived social contribution, could explain part of the effect of enacted extraversion on state PA. Though these findings provide a promising starting point, they raise as many questions as they answer. Whereas Keyes' (1998) social contribution measure emphasized worthwhile and valuable contributions to one's community, Smillie, Wilt, et al.'s “percent contributed” measure is conceptually 
ambiguous. Ratings may have reflected the extent to which participants felt that they directed the discussion (mere impact), contributed to the success of the exercise (useful contributions), or made the task enjoyable for others (positively contributing to others' well-being). Thus, although these findings indicate that those who act extraverted perceive that they have more impact on a social situation, it is unclear what kind of impact is involved.

Subjective social power (henceforth, power) may be a more general mechanism that underlies the social contribution effect. Power is defined as one's perceived ability to influence others - that is, to modify others' states (Anderson, John, \& Keltner, 2012; D. Keltner, Gruenfeld, Galinsky, \& Kraus, 2010). As power can stem from one's perceived freedom to deliver resources as well as punishments to others (Keltner, Gruenfeld, \& Anderson, 2003), it is more general than social contribution, which we define as perceptions of positive (i.e., useful or prosocial) impact (in line with Keyes, 1998). The two constructs therefore overlap in that social contribution can be thought of as a facet of social power. Extraverts have been shown to attain more influence in social interactions and the workplace (Anderson \& Berdahl, 2002; Anderson \& Kilduff, 2009; Anderson, Spataro, \& Flynn, 2008), and individuals assigned more power in laboratory-based interactions experienced and expressed more positive emotion (Berdahl \& Martorana, 2006; Langner \& Keltner, 2008). This suggests that power could plausibly mediate the extraversion-PA relation.

Our objective in the present research is to clarify the conceptual nature of the social contribution mediator identified by Smillie, Wilt, and colleagues (2015), and thereby sharply delineate the social processes that may help to explain the impact of extraverted behavior on PA. This is achieved in three ways. First, to examine the role of "positive impact", we employ measures of state social contribution that are explicitly framed in terms of positive contributions. Second, we examine the potential mediating role of a more general impactrelated process, power. Finally, we test the simultaneous mediating effects of social 
contribution and power to explore the unique and overlapping roles of "positive impact" (i.e., social contribution) compared with "general impact" (i.e., social power).

\section{Overview of Studies}

Across three studies, we test the hypotheses that (H1) social contribution and (H2) power mediate the relation between extraversion and PA. We also investigate the extent to which social contribution and power independently mediate the relation between extraversion and PA. As a preliminary test of our hypotheses, we first examine whether individual differences in social contribution and power mediate the relation between trait extraversion and trait PA (Study 1). We then investigate whether state levels of social contribution and power mediate the relations that experimentally manipulated extraverted behavior (Study 2) and natural fluctuations in extraverted behavior (Study 3) have with PA states. All methods received ethical approval at the University of Melbourne.

In accordance with recent recommendations surrounding research integrity (Simmons, Nelson, \& Simonsohn, 2012), we report how we determined our sample size, all manipulations, and all data exclusions. Additional measures that were unrelated to the current hypotheses, along with data and analysis scripts necessary to reproduce the results reported in this manuscript, are available at https://osf.io/rusxc.

\section{Study 1}

The current paper focuses on mediators of the state-level relation between extraverted behavior and PA states. However, Fleeson and colleagues (2002) have suggested that states and traits share important properties and consequences, such that state-level relations should mirror trait-level relations. The finding that trait extraversion and extraverted behavior are both associated with increased PA (e.g., Smillie, Wilt, et al., 2015) supports this state-trait isomorphism hypothesis. From this perspective, if our hypotheses apply to people who generally behave in a more extraverted way (i.e., trait extraverts), they should also apply 
when people are enacting extraverted behaviors. We therefore conducted a preliminary crosssectional study to investigate trait-level effects. Study 1 aimed to replicate Smillie, Wilt, et al.'s (2015, Study 1) finding that (H1) trait social contribution mediates the relation between trait extraversion and trait PA, and to test the new hypothesis that $(\mathrm{H} 2)$ trait power mediates the relation between trait extraversion and trait PA. To compare positive influence with general impact, we also explored whether social contribution and power independently mediate the trait extraversion-PA relation when entered as simultaneous mediators.

\section{Method}

Participants and procedure. Participants $(N=211)$ recruited via Amazon's Mechanical Turk (MTurk; see Buhrmester, Kwang, \& Gosling, 2011) completed the study in exchange for \$2 USD. To obtain more precise estimates of the effects and to achieve a similar sample size (i.e., $N=225$ ) as Smillie, Wilt, et al. (2015, Study 1), we added 59 observations after analyzing the first 147 (of 152) valid responses. Results changed very little after the addition of this second wave of data. Data collection for each wave ended automatically when the allocated number of MTurk assignments were completed. Due to multiple waves of data collection, we had 7 duplicate participants (based on WorkerIDs), but as we did not link WorkerIDs to survey responses, we could not exclude them. Data from six participants were excluded due to highly inconsistent responses between an original and repeated item (i.e., differing by $\geq 2$ scale points) designed to screen for inattention. This left a final sample of 205 participants (98 female) aged $18-66$ years $\left(M_{\mathrm{age}}=34.89, S D_{\mathrm{age}}=10.04\right)$. Participants completed a battery of trait questionnaires, including the following measures, programmed using Qualtrics ${ }^{\mathrm{TM}}$ survey software.

\section{Measures.}

Extraversion. Participants completed the 20-item extraversion scale from the Big Five Aspect Scales (DeYoung, Quilty, \& Peterson, 2007). This consists of two 10-item 
subscales measuring two distinct aspects of extraversion: assertiveness (agentic and bold behavior; e.g., "Take charge") and enthusiasm (affiliative experiences; e.g., "Make friends easily"). Participants indicated the extent to which they agreed that each statement described their personality $(1=$ strongly disagree, $5=$ strongly agree $)$.

Social contribution. Participants completed two measures of social contribution. First, participants completed the 3-item social contribution subscale (e.g., "I have something valuable to give the world"; 1 = strongly disagree, $5=$ strongly agree). Second, participants completed the 3-item Self-Worth subscale from the Comprehensive Inventory of Thriving (CIT; Su, Tay, \& Diener, 2014), which assesses subjective perceptions of valuable social contributions (e.g., "The things I do contribute to society"; 1 = strongly disagree, $5=$ strongly agree). As the two measures were conceptually similar and highly correlated $(r=$ $.69, p<.001)$, and the six items clearly loaded onto a single Principal Component that accounted for $66.1 \%$ of the variance (all loadings $\geq .74$ ), we combined all items into a single scale to increase measurement reliability, given the brevity of the individual measures.

Social power. The 8-item Sense of Power Scale (Anderson et al., 2012) measures subjective perceptions of power in social relationships. Thinking about their relationships with others, participants indicated the extent to which they agreed with each of the items (e.g., "I can get them to do what I want"; 1 = disagree strongly, 7 = agree strongly).

Positive affect. Participants completed the 20-item Positive and Negative Affect Schedule (PANAS; Watson, Clark, \& Tellegen, 1988), which contains a 10-item measure of activated PA (e.g., excited, enthusiastic) — the strongest affective correlate of trait extraversion (Smillie, DeYoung, \& Hall, 2015). Participants rated the extent to which they feel these affects in general $(1=$ very slightly or not at all, $5=$ extremely $)$.

Data Analysis. All analyses were conducted using SPSS Version 23, with the exception of omega $(\omega)$ reliability coefficients (McDonald, 1999), which were computed in R 
(R Core Team, 2016) using the MBESS package (Dunn, Baguley, \& Brunsden, 2014; Kelley \& Lai, 2012). Mediated regressions were deployed using the PROCESS Macro for SPSS (Hayes, 2013, 2014), which implements the bootstrapping procedures outlined by Preacher and Hayes (2008). We used 2,000 bootstrap samples to estimate bias-corrected standard errors and 95\% confidence intervals for the indirect effect of extraversion on PA via social contribution and power, and the difference between the two indirect effects. To facilitate effect size interpretation, indirect effects are described in-text as a percentage of the total effect of extraversion on PA (percent mediated effect [PME]; Preacher \& Kelley, 2011).

\section{Results and Discussion}

Preliminary analyses. Table 1 shows means, standard deviations, $\omega$ reliability estimates, and intercorrelations between measures. All scales had high internal consistency $(\omega \mathrm{s} \geq .89)$. All variables were also highly correlated, supporting the plausibility of the proposed mediation hypotheses.

Table 1

Descriptive Statistics, Scale Reliabilities ( $\omega)$ and Intercorrelations for Study 1

\begin{tabular}{lcccccccc}
\hline Variables & $M$ & $S D$ & 1 & 2 & 3 & 4 & 5 & 6 \\
\hline 1. Extraversion & 3.28 & 0.71 &. $\mathbf{9 2}$ & & & & & \\
2. Enthusiasm & 3.32 & 0.79 & .85 &. $\mathbf{8 9}$ & & & & \\
3. Assertiveness & 3.23 & 0.84 & .87 & .49 &. $\mathbf{9 2}$ & & & \\
4. Contribution & 3.61 & 0.88 & .56 & .50 & .47 &. $\mathbf{9 0}$ & & \\
5. Power & 4.81 & 1.25 & .71 & .55 & .66 & .62 & .92 & \\
6. Positive Affect & 3.60 & 0.89 & .60 & .56 & .47 & .49 & .50 & $\mathbf{. 9 3}$
\end{tabular}

Note. All $r$ s are significant at $p<.001 . \omega$ coefficients are displayed as bold values on the diagonal. 
Mediated regressions. Supporting Hypothesis 1 (and conceptually replicating Smillie, Wilt et al., 2015, Study 1), the indirect effect of extraversion on PA via social contribution was significant and accounted for $21 \%$ of the total effect of extraversion on PA (see Table 2, Model 1). Supporting Hypothesis 2, there was also a significant indirect effect of extraversion on PA via power (see Table 2, Model 2), accounting for $18 \%$ of the relation between extraversion and PA. When social contribution and power were entered together, the indirect effect via social contribution remained significant and of a similar magnitude (PME $=19 \%)$ as its indirect effect in the single-mediator model, but power was no longer a significant mediator (see Table 2, Model 3). However, the two indirect effects were not significantly different in magnitude.

Table 2

Key Mediated Regression Models Tested in Study 1

\begin{tabular}{|c|c|c|c|c|c|}
\hline Mediating Variables & $\begin{array}{l}\mathrm{IV} \rightarrow \mathrm{M} \\
(a \text { path })\end{array}$ & $\begin{array}{c}\mathrm{M} \rightarrow \mathrm{DV} \\
(b \text { path })\end{array}$ & $\begin{array}{l}\text { Direct effect } \\
\text { (c'path) }\end{array}$ & $\begin{array}{l}\text { Indirect effect } \\
(a \times b \text { path })\end{array}$ & $\begin{array}{c}95 \% \mathrm{CI} \text { of } \\
\text { indirect effect }\end{array}$ \\
\hline \multicolumn{6}{|l|}{ Model 1} \\
\hline Contribution & $0.70 * * *$ & $0.22 * *$ & $0.60 * * *$ & 0.15 & {$[0.08,0.25]$} \\
\hline \multicolumn{6}{|l|}{ Model 2} \\
\hline Power & $1.25 * * *$ & 0.11 & $0.62 * * *$ & 0.14 & {$[+0.00,0.29]$} \\
\hline \multicolumn{6}{|l|}{ Model 3} \\
\hline Contribution & $0.70 * * *$ & $0.20 * *$ & $0.55 * * *$ & 0.14 & {$[0.05,0.23]$} \\
\hline Power & $1.25 * * *$ & 0.05 & & 0.06 & {$[-0.08,0.21]$} \\
\hline Difference & & & & 0.08 & {$[-0.12,0.27]$} \\
\hline
\end{tabular}

At the aspect level (see Table 3), social contribution mediated a significant proportion of the relation between enthusiasm and $\mathrm{PA}(\mathrm{PME}=25 \%)$, and the relation between 
assertiveness and PA (PME $=34 \%)$. Power also mediated a significant proportion of the relation between enthusiasm and PA $(\mathrm{PME}=27 \%)$, and between assertiveness and PA (PME $=46 \%$ ). Unlike the domain-level results (see Table 2, Model 3), when entered together, social contribution and power both independently mediated the relations between enthusiasm and PA $\left(\mathrm{PME}_{\text {Contribution }}=17 \% ; \mathrm{PME}_{\text {Power }}=18 \%\right)$, and between assertiveness and PA $(\mathrm{PME}$ Contribution $=26 \% ; \mathrm{PME}_{\text {Power }}=26 \%$ ). Consistent with the domain-level results, the magnitudes of the two indirect effects were not significantly different for either aspect.

Table 3

Aspect-Level Mediated Regression Models Tested in Study 1

\begin{tabular}{|c|c|c|c|c|c|}
\hline Mediator & $\begin{array}{c}\mathrm{IV} \rightarrow \mathrm{M} \\
(a \text { path })\end{array}$ & $\begin{array}{c}\mathrm{M} \rightarrow \mathrm{DV} \\
(b \text { path })\end{array}$ & $\begin{array}{c}\text { Direct effect } \\
\text { (c'path) }\end{array}$ & $\begin{array}{l}\text { Indirect effect } \\
(a \times b \text { path })\end{array}$ & $\begin{array}{l}95 \% \mathrm{CI} \text { of } \\
\text { indirect effect }\end{array}$ \\
\hline \multicolumn{6}{|l|}{ Model $1_{\text {Enthusiasm }}$} \\
\hline Contribution & $0.55 * * *$ & $0.28 * * *$ & $0.47 * * *$ & 0.15 & {$[0.09,0.24]$} \\
\hline \multicolumn{6}{|l|}{ Model $1_{\text {Assertiveness }}$} \\
\hline Contribution & $0.49 * * *$ & $0.34 * * *$ & $0.33 * * *$ & 0.17 & {$[0.10,0.26]$} \\
\hline \multicolumn{6}{|l|}{ Model 2 Enthusiasm } \\
\hline Power & $0.86 * * *$ & $0.20 * * *$ & $0.46 * * *$ & 0.17 & {$[0.09,0.27]$} \\
\hline \multicolumn{6}{|l|}{ Model 2 Assertiveness } \\
\hline Power & $0.98 * * *$ & $0.23 * * *$ & $0.27 * *$ & 0.23 & {$[0.10,0.43]$} \\
\hline \multicolumn{6}{|l|}{ Model 3 Enthusiasm } \\
\hline Contribution & $0.55 * * *$ & $0.19 * *$ & $0.41 * * *$ & 0.11 & {$[0.04,0.18]$} \\
\hline Power & $0.86 * * *$ & $0.13 *$ & & 0.11 & {$[0.03,0.21]$} \\
\hline Difference & & & & 0.00 & {$[-0.15,0.12]$} \\
\hline \multicolumn{6}{|l|}{ Model 3 Assertiveness } \\
\hline Contribution & $0.49 * * *$ & $0.27 * *$ & $0.24 * * *$ & 0.13 & {$[0.07,0.22]$} \\
\hline Power & $0.98 * * *$ & $0.13^{*}$ & & 0.13 & {$[0.01,0.27]$} \\
\hline Difference & & & & 0.00 & {$[-0.16,0.16]$} \\
\hline
\end{tabular}

Note. ${ }^{* *} p<.01, * * * p<.001$. Indirect effects in bold denote that the $95 \%$ CI does not

capture zero. Subscripts denote the independent variable (Enthusiasm or Assertiveness). 


\section{Summary}

These results support our two hypotheses that individual differences in social contribution and power mediate the relation between trait extraversion and PA. Our social contribution finding conceptually replicates Smillie, Wilt, et al.’s (2015, Study 1) finding, using a longer measure of social contribution and a more diverse online sample. We additionally extend Smillie, Wilt, et al.'s (2015) social contribution finding by demonstrating that a related social impact process, social power, may also help to explain the relation between trait extraversion and PA. If the relations at the state level mirror those at the trait level (Fleeson et al., 2002), these findings suggest that social contribution and power might also mediate the relation between extraverted behavior and PA states. In Studies 2 and 3, we test these hypotheses directly, and also address a few remaining issues.

First, cross-sectional data do not permit inferences about causal direction, and indirect effects based only on self-ratings may be inflated by or even entirely attributed to common method variance (see Podsakoff, MacKenzie, Lee, \& Podsakoff, 2003). To address these limitations, Study 2 employs an experimental paradigm to investigate the causal effects of extraverted behavior on social contribution, power, and self- and informant-rated PA states. Multiple-mediator models in Study 1 also showed that as simultaneous mediators, social contribution remained a significant mediator, but power no longer significantly mediated the extraversion-PA relation. At the aspect level, however, social contribution and power both independently mediated the enthusiasm-PA and assertiveness-PA relations. Studies 2 and 3 therefore continue to compare the extent to which both types of impact mediate the extraversion-PA relation.

\section{Study 2}

Study 2 employs an experimental design to test whether social contribution and power mediate the effect of experimentally-manipulated extraverted behavior on self- and 
informant-rated PA states. This experiment closely replicates the protocol employed by Smillie, Wilt, et al. (2015, Study 2), while employing an improved measure of state contribution; instead of a single-item percentage rating, the present experiment uses a multiitem state measure derived from Keyes' (1998) social contribution construct (see Study 1). Encouraged by the trait-level findings in Study 1, we hypothesized that (H1) social contribution and (H2) power would also mediate the effect of acting extraverted on PA in single-mediator models. We also tested multiple-mediator models to clarify the extent to which social contribution and power independently mediate this effect.

\section{Method}

Participants and procedure. Participants $(N=84)$ were recruited through the undergraduate psychology participant pool at the University of Melbourne, as well as flyers placed around the university. This represents an oversampling of our target sample size of 81 , to match Smillie, Wilt, et al. (2015, Study 2). However, four participants did not show up. We also excluded one legally blind participant and one participant who had incomplete data. The final sample $(N=78 ; 61$ female) therefore comprised 63 first-year psychology students (in exchange for course credit) and 15 members of the general public (compensated with $\$ 15$ AUD cash), aged $18-40$ years $\left(M_{\text {age }}=20.22, S D_{\text {age }}=3.56\right)$.

Participants were tested in groups of three or two (in four sessions where one participant did not show up). After providing informed consent, participants completed several trait questionnaires via Qualtrics ${ }^{\mathrm{TM}}$. They were then randomly assigned to one of three (acting extraverted, acting introverted, and uninstructed control; for complete groups) or two conditions (no uninstructed condition; for incomplete groups) via written instructions on how to interact with the other participants during the discussion tasks (described below). After data exclusions (described above), the final analyses were based on 22 groups of three 
and six groups of two, comprising 22 uninstructed participants and 28 participants in each of the acting extraverted and acting introverted conditions.

Seated in a circle, participants were given 15 minutes to complete each of two group discussion tasks (described below). After the first discussion (T1), participants independently completed paper-based state measures, including measures of their extraverted behavior, social contribution, power, and PA during the group discussion. All participants also provided informant ratings of other participants' states. Participants then completed a second group discussion task, followed by the same state measures pertaining to experiences during the second discussion task (T2). Finally, participants were debriefed and thanked.

\section{Measures and materials.}

Behavioral instructions. Participants received individual behavioral instructions as part of the general written instructions for the two discussion tasks. As in previous studies (e.g., Fleeson et al., 2002; Smillie, Wilt, et al., 2015; Zelenski et al., 2012), participants in the acting extraverted condition were instructed to act bold, talkative, energetic, assertive, and adventurous, whereas participants in the acting introverted condition were instructed to act reserved, quiet, lethargic, passive, compliant, and unadventurous during the two discussion tasks. In place of acting instructions, participants in the uninstructed condition were given slightly extended (but informationally-equivalent) task instructions to ensure that all participants spent an equal amount of time reading their instructions. Participants were asked not to share their instructions with anyone else in the group.

Group discussion tasks. The two "Survival on the Moon" and "Lost at Sea" discussion tasks (with the order counterbalanced between groups) were based on problemsolving exercises used in previous enacted extraversion studies (e.g., Fleeson et al., 2002; Smillie, Wilt, et al., 2015). Participants discussed and collaboratively ranked the usefulness of 15 items in scenarios that involved being stranded in space or adrift at sea on a ship. 
Trait and state extraversion. Trait extraversion was measured using the same measure as in Study 1. State extraversion was measured after each discussion task. Ten wellvalidated adjectives that described extraverted behavior (shy $[\mathrm{r}]$, compliant $[\mathrm{r}]$, reserved $[\mathrm{r}]$, lethargic [r], bold, talkative, energetic, active, assertive, adventurous; Goldberg, 1992) were mixed with filler adjectives (e.g., practical, imaginative). Participants rated the extent to which these adjectives described their behavior and the behavior of the other two participants during the task $(1=$ not at all, $7=$ very well $)$. Extraversion items did not simply duplicate behavioral instructions, but included additional adjectives (e.g., active, reserved).

State PA. State PA was measured immediately after each discussion task. Participants rated the extent to which they felt each of 10 PANAS PA adjectives (described in Study 1; 1 $=$ very slightly or not at all, $7=$ extremely) during the group discussion. They also rated the extent to which they thought the other participants felt these emotions during the discussion.

State social contribution. To create a state measure of social contribution, we adapted items from the two measures described in Study 1 (Keyes, 1998; Su et al., 2014). Participants rated how well three items described their experience ("My contributions to the discussion were worthwhile"; "I had nothing to contribute to the social interaction" [r]; "My input to this exercise was important"; 1 = not at all, 7 = very well). Due to the subjective nature of this construct, informant ratings were not collected (in line with Smillie, Wilt, et al., 2015).

State social power. After each discussion task, participants rated two items adapted from Langner and Keltner (2008): "I had power in the discussion" and "I had control over the discussion" ( 1 = disagree strongly, 7 = agree strongly $)$. Participants also rated the power and control that the other two participants had during the discussions.

Data analyses. Each participant had two ratings of contribution (self-ratings at T1 and T2) and up to six separate ratings of state extraversion, PA, and power (self- and informant ratings at $\mathrm{T} 1$ and $\mathrm{T} 2$ ). As participants had the same acting instructions for both 
discussion tasks, we combined ratings across the two time points to increase measurement reliability (except for time-lagged analyses). To further increase measurement reliability and decrease the bias associated with self-report (e.g., common method variance), we also combined self- and all available informant ratings, and focus on describing analyses involving these total composites. To provide additional information and to assess the robustness of the results across different indices, we also report results for analyses that used self-ratings only, uninstructed informant ratings only, all available informant ratings (henceforth, multiple-informant composite), and composites comprising self- and uninstructed informant ratings (henceforth, self-uninstructed composite). The exception is that mediation analyses were always conducted using self-reported mediators (contribution or power), as we did not obtain informant reports of contribution. This was to ensure that mediation analyses were comparable for the two mediators.

Although we did not conduct an a priori power analysis in planning this study, it is informative to provide context on the effect sizes that could reasonably be detected using our final sample size. A G*Power (Faul, Erdfelder, Lang, \& Buchner, 2007) analysis reveals that the sample sizes per condition required for $80 \%$ power to detect "large" $(d=0.80)$, "medium" $(d=0.50)$, and "small" $(d=0.20)$ effects (Cohen, 1992) are 26, 64, and 394, respectively. With an average sample size of 26 per condition, we therefore had around $80 \%$ power to detect differences greater than $d=0.80$, which is in line with previous estimates of the effect of acting extraverted on self-rated PA (e.g., Fleeson et al., 2002; McNiel \& Fleeson, 2006; Smillie, Wilt, et al., 2015).

Power analysis for mediation models is more complex. However, one simulation study (Fritz \& MacKinnon, 2007) suggests that, using the bias-corrected bootstrap method, around 34 participants are needed for $80 \%$ power to detect an indirect effect when the $a$ (independent variable to mediator) and $b$ (mediator to dependent variable) paths are both 
large, around 53 participants are needed if one path is large and the other medium, and around 71 participants are needed if both paths are medium. However, if both paths are small, over 462 participants are needed to detect the indirect effect. Assuming that these guidelines apply to this specific case, our mediation analyses comprising 56 participants (for the total, self, and multiple-informant composites) had sufficient power to detect indirect effects when one path was large and the other was at least medium in magnitude. However, analyses comprising 44 participants (for the uninstructed informant and self-uninstructed composites) only had enough power to detect indirect effects based on two large paths.

Descriptive statistics and $\omega$ reliability coefficients were computed using SPSS Version 23 and R, respectively (as described in Study 1). We also used the rpsychi package for R (Okumura, 2012) to compute unbiased standardized mean differences (Hedges' $g$ ) and 95\% confidence intervals. Although participants were nested within groups, we had no group-level predictions, and the intraclass correlations $(I C C(1))$ for all state variables were extremely small $(\leq .003)$ for all variables apart from state PA reported by uninstructed informants $(\mathrm{T} 1=.12 ; \mathrm{T} 2=.02$; combined $=.06)$, suggesting that the group structure accounted for virtually zero variance in most variables. We therefore used the PROCESS Macro for SPSS (as described in Study 1) to conduct standard mediated and moderated regression analyses (with condition coded as $0=$ acting introverted, $1=$ acting extraverted).

\section{Results}

Preliminary analyses. As shown in Table 4, all trait and state measures had high internal consistency $(\omega \mathrm{s} \geq .88)$, whether participants were rating themselves or others. ICC(1)s for all state extraversion and power composites showed good interrater agreement (Cicchetti, 1994) at separate time points ( $\geq .65)$, and excellent agreement when combined across both time points $(\geq .85)$. Although $I C C(1)$ s for state PA at separate time points ranged from nearly no agreement (.09) to good agreement (.68), the combined $I C C(1) \mathrm{s}$ across the 
two time points were in the good to excellent range $(\geq .72)$. Test-retest stability was also high for all indices, as shown by high correlations $(\geq .79)$ between scores after the first and second discussion tasks (see Table 4). Nevertheless, as composites averaged across all available ratings showed the highest interrater agreement, analyses that use the total composites averaged across both time points may produce more robust results than analyses that use alternative indices or individual time points.

Manipulation checks. We proceeded to examine whether participants in the two acting conditions followed instructions to act extraverted or introverted. Although uninstructed participants primarily served as relatively unbiased informants, we also calculated unbiased Hedges' $g$ standardized effect sizes to investigate whether participants in the acting conditions enacted higher or lower levels of extraversion, relative to those who received no acting instructions. These estimates (see Table 5) revealed no significant differences in trait extraversion between the three conditions, suggesting that between-group differences on state extraversion (and PA) would not likely be due to trait influences.

As expected, state extraversion differed between conditions (see Table 5). Participants in the acting extraverted condition indeed acted significantly more extraverted than participants in the acting introverted condition (across all indices), and this difference ranged from 1.35 (uninstructed informant ratings) to 3.30 standard deviations (self-ratings) in magnitude. Uninstructed informants also had significantly higher levels of state extraversion than participants instructed to act introverted (across all indices), with effect sizes ranging from 1.05 (uninstructed informant ratings) to 2.51 standard deviations (self-ratings). It is particularly notable that even uninstructed informants, who were unaware of the existence of acting instructions, noticed these differences. Although the effect sizes reported by the uninstructed informants were much smaller compared to those produced by self-ratings, these relatively naïve informant ratings arguably provide a particularly strong manipulation check. 
Table 4

Means, Standard Deviations, Reliability Estimates ( $\omega)$, Interrater Agreement (ICC(1)), and Test-Retest Reliability (r) of Key Measures in Study 2

\begin{tabular}{|c|c|c|c|c|c|c|c|c|c|}
\hline & \multicolumn{3}{|c|}{$M(S D)$} & \multicolumn{2}{|c|}{$\omega$} & \multicolumn{3}{|c|}{$I C C(1)$} & \multirow{2}{*}{$\begin{array}{l}\text { Test-retest } \\
\text { reliability }\end{array}$} \\
\hline & Act $\mathrm{E}$ & Act I & Uninstructed & $\mathrm{T} 1$ & $\mathrm{~T} 2$ & $\mathrm{~T} 1$ & $\mathrm{~T} 2$ & Combined & \\
\hline Trait extraversion & $3.57(0.41)$ & $3.46(0.63)$ & $3.48(0.45)$ & \multicolumn{2}{|c|}{.88} & - & - & - & - \\
\hline Total & $5.13(0.50)$ & $3.07(1.02)$ & $4.73(0.77)$ & - & - & .81 & .83 & .91 & .92 \\
\hline Self & $5.32(0.66)$ & $2.54(1.06)$ & $4.72(0.83)$ & .93 & .95 & - & - & - & .92 \\
\hline Self-uninstructed & $5.15(0.52)$ & $3.14(0.89)$ & - & - & - & .70 & .66 & .87 & .90 \\
\hline \multicolumn{10}{|l|}{ State positive affect } \\
\hline Total & $4.60(0.65)$ & $3.12(0.86)$ & $4.44(0.83)$ & - & - & .57 & .68 & .83 & .89 \\
\hline Self & $4.63(0.87)$ & $2.80(1.29)$ & $4.37(1.16)$ & .93 & .95 & - & - & - & .79 \\
\hline \multicolumn{10}{|l|}{ State contribution } \\
\hline Self & $5.88(0.74)$ & $3.54(1.53)$ & $5.47(0.85)$ & .88 & .88 & - & - & - & .80 \\
\hline \multicolumn{10}{|l|}{ State power } \\
\hline Total & $5.36(0.89)$ & $2.79(1.33)$ & $4.50(1.07)$ & - & - & .82 & .81 & .91 & .88 \\
\hline Self & $5.58(1.20)$ & $2.60(1.52)$ & $4.60(1.19)$ & .89 & .92 & - & - & - & .84 \\
\hline Uninstructed informant & $5.13(0.97)$ & $3.44(1.50)$ & - & - & - & - & - & - & .80 \\
\hline Multiple informants & $5.25(0.90)$ & $2.90(1.38)$ & $4.44(1.23)$ & .90 & .93 & .72 & .68 & .85 & .82 \\
\hline Self-uninstructed & $5.34(0.88)$ & $3.05(1.37)$ & - & - & - & .81 & .76 & .92 & .91 \\
\hline
\end{tabular}

Note. Act E = Acting Extraverted; Act I = Acting Introverted; T1 = After Discussion 1; T2 = After Discussion 2. $p$ s for test-retest $r$ all $<.001$. 
Table 5

Unbiased Standardized Mean Differences (Hedges'g) Between Conditions

\begin{tabular}{lccccc}
\hline Contrast & Total & Self & $\begin{array}{c}\text { Uninstructed } \\
\text { informant }\end{array}$ & $\begin{array}{c}\text { Multiple } \\
\text { informants }\end{array}$ & $\begin{array}{c}\text { Self- } \\
\text { uninstructed }\end{array}$ \\
\hline Trait E & & & & \\
Act E - Act I & - & 0.22 & - & - & - \\
& & {$[-0.31,0.75]$} & & - & - \\
Act E - & - & 0.19 & - & - \\
Uninstructed & & {$[-0.38,0.76]$} & & - \\
Uninstructed & - & 0.03 & - & \\
- Act I & & {$[-0.54,0.60]$} & &
\end{tabular}

State E

$\begin{array}{lccccc}\text { Act E - Act I } & \mathbf{2 . 6 0} & \mathbf{3 . 3 0} & \mathbf{1 . 3 5} & \mathbf{1 . 9 0} & \mathbf{2 . 6 4} \\ & {[2.06,3.13]} & {[2.67,3.74]} & {[0.75,1.96]} & {[1.36,2.43]} & {[2.03,3.24]} \\ & & & & & \\ \text { Act E - } & 0.50 & \mathbf{0 . 6 9} & 0.31 & 0.30 & 0.56 \\ \text { Uninstructed } & {[-0.07,1.07]} & {[0.12,1.26]} & {[-0.30,0.91]} & {[-0.27,0.87]} & {[-0.04,1.16]} \\ & & & & & \\ \text { Uninstructed } & \mathbf{2 . 1 0} & \mathbf{2 . 5 1} & \mathbf{1 . 0 5} & \mathbf{1 . 6 0} & \mathbf{2 . 0 8} \\ \text { - Act I } & {[1.53,2.66]} & {[1.95,3.08]} & {[0.45,1.65]} & {[1.03,2.16]} & {[1.48,2.68]}\end{array}$

State PA

Act E - Act I

1.90

1.64

$\mathbf{0 . 8 2}$

1.37

1.56

$[1.37,2.43] \quad[1.11,2.17] \quad[0.22,1.43] \quad[0.84,1.90] \quad[0.96,2.16]$

Act E -

0.20

0.24

0.17

0.07

0.22

Uninstructed

$[-0.36,0.77]$

$[-0.33,0.80]$

$[-0.44,0.77]$

$[-0.49,0.64]$

$[-0.38,0.82]$

Uninstructed

1.70

1.40

0.66

1.30

1.34

- Act I

$[1.13,2.26]$

$[0.84,1.97] \quad[0.06,1.26]$

$[0.73,1.87]$

$[0.74,1.94]$

Note. 95\% confidence intervals are shown in brackets. Coefficients in bold denote that the 95\% CI does not capture zero. For uninstructed participants, uninstructed informant and selfuninstructed composites were self-ratings.

Finally, although participants in the acting extraverted condition had higher point estimates of extraverted behavior relative to uninstructed controls, these differences were 
much smaller, ranging from 0.30 (all informant ratings) to 0.69 standard deviations (selfratings), and this difference was only significant for self-rated extraverted behavior.

Enacted extraversion and positive affect. We also compared differences in state PA between participants in the three conditions (see Table 5). The pattern of findings was very similar to those for extraverted behavior. As expected, participants in the acting extraverted condition had significantly higher levels of state PA than participants in the acting introverted condition (across all indices), and this difference ranged from 0.82 (uninstructed informant ratings) to 1.90 standard deviations (total composite) in magnitude. Uninstructed controls also had significantly higher levels of state PA than participants instructed to act introverted (across all indices), with effect sizes ranging from 0.66 (uninstructed informant ratings) to 1.70 standard deviations (total composite). Again, however, participants in the acting extraverted condition only had slightly higher point estimates for state PA relative to uninstructed participants, and none of these differences were statistically detectable.

We then tested whether trait levels of extraversion moderated the effect of acting extraverted (vs. acting introverted) on PA. A series of moderated regressions revealed that trait extraversion did not predict levels of state PA, and the interaction between trait extraversion and condition was non-significant (for all indices; see Table 6). Thus, there was no evidence that extraverts and introverts differed in the extent to which they enjoyed enacting extraverted behaviors. Although we cannot rule out small interaction effects (given the statistical power provided by the current sample size), the lack of a significant interaction is consistent with all previous studies that have reported this analysis $(\mathrm{McNiel} \&$ Fleeson, 2006; Smillie, Wilt, et al., 2015; Zelenski et al., 2012; Zelenski et al., 2013). 
Table 6

Moderated Regressions Predicting Positive Affect from Acting Condition

\begin{tabular}{lccccc}
\hline & Total & Self & $\begin{array}{c}\text { Uninstructed } \\
\text { informant }\end{array}$ & $\begin{array}{c}\text { Multiple } \\
\text { informants }\end{array}$ & $\begin{array}{c}\text { Self- } \\
\text { uninstructed }\end{array}$ \\
\hline $\begin{array}{l}\text { Condition } \rightarrow \\
\text { State PA }\end{array}$ & $1.44^{* * *}$ & $1.78^{* * *}$ & $0.89^{* *}$ & $1.23^{* * *}$ & $1.39^{* * *}$ \\
& {$[1.04,1.84]$} & {$[1.19,2.37]$} & {$[0.22,1.55]$} & {$[0.74,1.73]$} & {$[0.93,1.85]$} \\
Trait E $\rightarrow$ State & 0.30 & 0.10 & 0.31 & 0.42 & 0.21 \\
PA & {$[-0.16,0.76]$} & {$[-0.57,0.77]$} & {$[-0.40,1.01]$} & {$[-0.14,0.98]$} & {$[-0.28 .0 .70]$} \\
Condition $\mathrm{x}$ & 0.20 & 0.71 & -0.16 & -0.12 & 0.34 \\
Trait PA & {$[-0.65,1.04]$} & {$[-0.52,1.94]$} & {$[-1.46,1.14]$} & {$[-1.15,0.91]$} & {$[-0.56,1.25]$} \\
& & & & & \\
\hline Note. ${ }^{*} p<.05, * * p<.01, * * * p<.001 .95 \%$ confidence intervals shown in brackets.
\end{tabular}

Mediated regressions. Supporting Hypothesis 1, our first mediation model (see

Table 7, Model 1) demonstrated that social contribution significantly mediated the effect of acting extraverted on total $(\mathrm{PME}=61 \%)$, self-report $(\mathrm{PME}=73 \%)$, multiple-informant $(\mathrm{PME}=56 \%)$, and self-uninstructed $(\mathrm{PME}=55 \%)$ PA indices. Likewise, supporting Hypothesis 2, our second model (see Table 7, Model 2) demonstrated that power significantly mediated the effect of acting extraverted on total $(\mathrm{PME}=59 \%)$, self-report $(\mathrm{PME}=65 \%)$, multiple-informant $(\mathrm{PME}=59 \%)$, and self-uninstructed $(\mathrm{PME}=51 \%) \mathrm{PA}$ indices.

The results of the multiple-mediator models (see Table 7, Model 3) largely mirrored the domain-level findings of Study 1. When social contribution and power were entered together as simultaneous mediators, contribution, but not power, remained a significant mediator for total $(\mathrm{PME}=47 \%)$, self-report $(\mathrm{PME}=63 \%)$, and self-uninstructed $(\mathrm{PME}=$ 48\%) PA indices. Once again mirroring Study 1, the differences between the pairs of indirect effects were not statistically significant. 
Table 7

Key Mediated Regression Models Tested in Study 2

\begin{tabular}{|c|c|c|c|c|c|c|c|c|c|c|}
\hline & \multicolumn{5}{|c|}{ Combined Time Points } & \multicolumn{5}{|c|}{ Lagged Time Points } \\
\hline & Total & Self & $\begin{array}{c}\text { Uninstructed } \\
\text { informant }\end{array}$ & $\begin{array}{c}\text { Multiple } \\
\text { informants }\end{array}$ & $\begin{array}{c}\text { Self- } \\
\text { uninstructed }\end{array}$ & Total & Self & $\begin{array}{c}\text { Uninstructed } \\
\text { informant }\end{array}$ & $\begin{array}{c}\text { Multiple } \\
\text { informants }\end{array}$ & $\begin{array}{c}\text { Self- } \\
\text { uninstructed }\end{array}$ \\
\hline \multicolumn{11}{|l|}{$\begin{array}{l}\text { Model } 1 \\
\text { (Contribution) }\end{array}$} \\
\hline $\mathrm{IV} \rightarrow \mathrm{M}$ & $2.34 * * *$ & $2.34 * * *$ & $2.32 * * *$ & $2.34 * * *$ & $2.32 * * *$ & $0.98 *$ & $1.22 * *$ & $1.91 * * *$ & $1.55 * * *$ & $1.13 *$ \\
\hline $\mathrm{M} \rightarrow \mathrm{DV}$ & $0.39 * * *$ & $0.57 * * *$ & 0.09 & $0.30 * *$ & $0.34 * * *$ & $0.14^{*}$ & $0.31 * *$ & 0.11 & 0.08 & $0.16^{*}$ \\
\hline Direct effect & $0.58 *$ & 0.50 & 0.70 & 0.56 & $0.64 *$ & $0.53 * *$ & $0.76^{*}$ & 0.03 & $0.45^{*}$ & 0.48 \\
\hline Indirect effect & $\begin{array}{c}\mathbf{0 . 9 1} \\
{[0.59,1.30]}\end{array}$ & $\begin{array}{c}\mathbf{1 . 3 3} \\
{[0.85,1.91]}\end{array}$ & $\begin{array}{c}0.21 \\
{[-0.41,0.93]}\end{array}$ & $\begin{array}{c}\mathbf{0 . 7 1} \\
{[0.32,1.21]}\end{array}$ & $\begin{array}{c}\mathbf{0 . 7 9} \\
{[0.42,1.29]}\end{array}$ & $\begin{array}{c}\mathbf{0 . 1 4} \\
{[0.01,0.40]}\end{array}$ & $\begin{array}{c}\mathbf{0 . 3 7} \\
{[0.09,0.85]}\end{array}$ & $\begin{array}{c}0.21 \\
{[-0.04,0.53]}\end{array}$ & $\begin{array}{c}0.12 \\
{[-0.07,0.39]}\end{array}$ & $\begin{array}{c}\mathbf{0 . 1 8} \\
{[0.01,0.62]}\end{array}$ \\
\hline \multicolumn{11}{|l|}{$\begin{array}{l}\text { Model } 2 \\
\text { (Power) }\end{array}$} \\
\hline $\mathrm{IV} \rightarrow \mathrm{M}$ & $2.98 * * *$ & $2.98 * * *$ & $2.91 * * *$ & $2.98 * * *$ & $2.91 * * *$ & $1.70 * * *$ & $2.05 * * *$ & $2.71 * * *$ & $2.18 * * *$ & $2.00 * *$ \\
\hline $\mathrm{M} \rightarrow \mathrm{DV}$ & $0.30 * * *$ & $0.40 * * *$ & 0.04 & $0.25 * *$ & $0.25 * *$ & $0.12 *$ & 0.13 & $0.15 *$ & $0.14 * *$ & $0.15^{*}$ \\
\hline Direct effect & $0.60^{*}$ & 0.64 & 0.80 & 0.52 & $0.69 *$ & $0.47 *$ & $0.86^{*}$ & -0.16 & 0.27 & 0.36 \\
\hline Indirect effect & $\begin{array}{c}\mathbf{0 . 8 8} \\
{[0.50,1.35]}\end{array}$ & $\begin{array}{c}\mathbf{1 . 1 9} \\
{[0.58,1.87]}\end{array}$ & $\begin{array}{c}0.11 \\
{[-0.57,0.82]}\end{array}$ & $\begin{array}{c}\mathbf{0 . 7 5} \\
{[0.38,1.36]}\end{array}$ & $\begin{array}{c}\mathbf{0 . 7 3} \\
{[0.31,1.40]}\end{array}$ & $\begin{array}{c}\mathbf{0 . 2 0} \\
{[0.01,0.51]}\end{array}$ & $\begin{array}{c}0.27 \\
{[-0.03,0.76]}\end{array}$ & $\begin{array}{c}\mathbf{0 . 3 9} \\
{[0.09,0.70]}\end{array}$ & $\begin{array}{c}\mathbf{0 . 3 0} \\
{[0.03,0.66]}\end{array}$ & $\begin{array}{c}\mathbf{0 . 3 0} \\
{[0.05,0.73]}\end{array}$ \\
\hline \multicolumn{11}{|l|}{ Model 3 (Both) } \\
\hline $\mathrm{IV} \rightarrow \mathrm{M} 1$ & $2.34 * * *$ & $2.34 * * *$ & $2.32 * * *$ & $2.34 * * *$ & $2.32 * * *$ & $0.98 *$ & $1.22 * *$ & $1.91 * * *$ & $1.55 * * *$ & $1.13^{*}$ \\
\hline $\mathrm{IV} \rightarrow \mathrm{M} 2$ & $2.98 * * *$ & $2.98 * * *$ & $2.91 * * *$ & $2.98 * * *$ & $2.91 * * *$ & $1.70 * * *$ & $2.05 * * *$ & $2.71 * * *$ & $2.18 * * *$ & $2.00 * *$ \\
\hline $\mathrm{M} 1 \rightarrow \mathrm{DV}$ & $0.30 * *$ & $0.49 * * *$ & 0.12 & 0.20 & $0.29 * *$ & 0.10 & $0.29 *$ & 0.03 & 0.03 & 0.10 \\
\hline $\mathrm{M} 2 \rightarrow \mathrm{DV}$ & 0.12 & 0.10 & -0.04 & 0.13 & 0.06 & 0.08 & 0.03 & 0.13 & $0.14 *$ & 0.11 \\
\hline Direct effect & 0.44 & 0.38 & 0.75 & 0.41 & 0.57 & $0.42 *$ & $0.71 *$ & -0.17 & 0.27 & 0.34 \\
\hline Indirect effect & 0.70 & 1.15 & 0.27 & 0.48 & 0.68 & 0.10 & 0.35 & 0.05 & 0.01 & 0.11 \\
\hline via M1 & {$[0.29,1.17]$} & {$[0.62,1.81]$} & {$[-0.38,1.21]$} & {$[-0.10,1.11]$} & {$[0.29,1.20]$} & {$[-0.04,0.37]$} & {$[0.05,0.89]$} & {$[-0.28,0.42]$} & {$[-0.27,0.22]$} & {$[-0.08,0.54]$} \\
\hline Indirect effect & 0.34 & 0.30 & -0.12 & 0.38 & 0.18 & 0.14 & 0.07 & 0.36 & 0.30 & 0.22 \\
\hline via M2 & {$[-0.09,0.84]$} & {$[-0.32,0.87]$} & {$[-0.96,0.58]$} & {$[-0.18,1.01]$} & {$[-0.28,0.71]$} & {$[-0.07,0.42]$} & {$[-0.39,0.43]$} & {$[-0.13,0.73]$} & {$[-0.01,0.66]$} & {$[-0.14,0.63]$} \\
\hline Difference & $\begin{array}{c}0.35 \\
{[-0.47,1.17]}\end{array}$ & $\begin{array}{c}0.84 \\
{[-0.08,2.00]}\end{array}$ & $\begin{array}{c}0.39 \\
{[-0.76,1.98]}\end{array}$ & $\begin{array}{c}0.09 \\
{[-1.02,1.24]}\end{array}$ & $\begin{array}{c}0.50 \\
{[-0.19,1.34]}\end{array}$ & $\begin{array}{c}-0.04 \\
{[-0.39,0.29]}\end{array}$ & $\begin{array}{c}0.29 \\
{[-0.29,1.07]}\end{array}$ & $\begin{array}{c}-0.31 \\
{[-0.86,0.54]}\end{array}$ & $\begin{array}{c}-0.29 \\
{[-0.76,0.19]}\end{array}$ & $\begin{array}{c}-0.11 \\
{[-0.67,0.47]}\end{array}$ \\
\hline
\end{tabular}

Note. $* p<.05, * * p<.01, * * * p<.001$. M1 = Contribution, M2 = Power. 95\% confidence intervals shown in brackets. Indirect effects in bold typeface indicate that the $95 \%$ confidence interval does not capture zero. 
One potential concern is that our mediators and dependent variables were measured at overlapping time points. As time-ordered lagged analyses enable stronger directional inferences, and therefore a stronger test of mediation (Fritz \& MacKinnon, 2007; Shrout \& Bolger, 2002), we used ratings of social contribution and power after the first discussion (T1) as the mediator, and PA states after the second discussion (T2) as the dependent variable, while controlling for PA states at T1. These lagged analyses (see Table 7) revealed that social contribution (Model 1) significantly mediated the effect of acting extraverted on PA in the single-mediator model for the total $(\mathrm{PME}=21 \%)$, self-report $(\mathrm{PME}=33 \%)$, and selfuninstructed PA indices $(\mathrm{PME}=27 \%)$, whereas power $($ Model 2$)$ was a significant mediator for the total $(\mathrm{PME}=30 \%)$, uninstructed informant (PME not applicable), multiple-informant $(\mathrm{PME}=53 \%)$, and self- uninstructed indices $(\mathrm{PME}=45 \%)$

When entered as simultaneous mediators (see Table 7, Model 3), social contribution $(\mathrm{PME}=31 \%)$, but not power, was a significant mediator for the self-report PA measure, although the two indirect effects were not significantly different in magnitude. Neither contribution nor power were significant mediators for the remaining PA indices, perhaps due to insufficient statistical power to detect the relatively smaller indirect effects on T2 PA after partialling out variance explained by T1 PA.

\section{Summary}

These results continue to bolster the well-replicated effect that acting extraverted has on PA (see Smillie, 2013). Supporting Hypothesis 1, we conceptually replicated the recent finding that social contribution mediates this effect (Smillie, Wilt, et al., 2015, Study 2), using an improved measure of the social contribution construct. Supporting Hypothesis 2, and conceptually replicating our trait-level findings in Study 1, we also found a significant mediating effect of power. Consistent with the domain-level findings in Study 1, however, power was generally no longer a significant mediator when entered simultaneously with 
social contribution. In contrast, social contribution tended to remain a significant mediator. Taken together, these findings clarify the results of Study 1 by suggesting that perceptions of "positive impact" may have a more robust role than "general impact" in explaining why extraverts report greater levels of PA in general.

Study 2 has three key strengths relative to the cross-sectional self-report design of Study 1 . The principal strength of the experimental paradigm used in this study is that it allows us to draw stronger causal inferences about the effect of acting extraverted on social contribution, power, and PA. Although we did not manipulate the mediators, lagged analyses also demonstrated that $\mathrm{T} 1$ social contribution or power (in single-mediator models) had downstream effects on most T2 composite measures of PA, controlling for T1 PA. Finally, by obtaining both self- and informant ratings, we were able to demonstrate that self-reported social contribution mediated the effect of acting extraverted on PA rated by multiple informants. As these ratings came from different individuals, this suggests that these indirect effects are not an artifact of common method variance.

However, a few issues remain unresolved. First, we recognize that our study had limited statistical power, sufficient only to detect medium to large indirect effects. As we were conceptually replicating effects demonstrated in a previous experimental study (Smillie, Wilt et al., 2015), as well as Study 1, we are less concerned about the effects being false positives. However, the small sample size did not provide sufficient statistical power to detect smaller effects, such as the difference between the indirect effect via social contribution and the indirect effect via power. The intensive repeated measures design of Study 3 provides greater statistical power to address this question.

Second, although an experimental design allows us to draw stronger causal inferences, this comes at a cost to ecological validity: it is possible that the mediating effects of social contribution and power may be meaningfully different outside of an artificial group 
problem-solving context. Relatedly, although the social contribution measure used in this study improved upon Smillie, Wilt, et al.'s (2015, Study 2) “percent contributed” measure, it was still framed in terms of contributions to arguably trivial laboratory tasks. This taskspecific measure may not have adequately captured Keyes' (1998) conceptualization of social contribution, which emphasized general perceptions of social value and contributions to one's community. In Study 3, we address these limitations by employing a naturalistic ESM paradigm and a modified version of the social contribution measure used in the present study.

\section{Study 3}

In Study 3, we move out of the lab and into the real world to investigate whether state levels of social contribution and power mediate the relation between natural fluctuations in extraverted behavior and PA states across a range of time points and situations in everyday life. We also employ an adapted state measure of social contribution that captures general perceptions of social value and beneficial impacts on other people. These extensions allow us to assess the extent to which the results of Study 2 generalize to daily life, while enabling a more faithful operationalization of Keyes' (1998) social contribution construct. Again, we hypothesized that $(\mathrm{H} 1)$ social contribution and $(\mathrm{H} 2)$ power would mediate the relation between extraverted behavior and PA in single-mediator models. Based on the results of Studies 1 and 2, we also hypothesized that (H3) when entered as simultaneous mediators, only social contribution would remain a significant mediator. Finally, the large number of momentary observations provide greater statistical power to examine whether the indirect effect via social contribution was larger than the indirect effect via power.

\section{Method}

Participants. Participants $(N=76)$ were recruited via flyers posted around the University of Melbourne. All participants were compensated with \$20 cash, and those who completed at least $75 \%$ of the ESM reports and the final survey also received a \$20 iTunes 
voucher and entry into a lottery to win one of six $\$ 100$ iTunes or Apple Store vouchers. A priori power analysis for multilevel models (see Bolger, Stadler, \& Laurenceau, 2012) requires information about many parameters that were not available from the single-level results of Studies 1 and 2. We instead set a minimum target sample of $N=60$ based on recommendations for avoiding biased estimates of Level 2 standard errors in multilevel modeling (Kreft \& de Leeuw, 1998; Maas \& Hox, 2005). Oversampling was required to replace unusable data (e.g., due to technical difficulties), and data collection ended when we obtained complete data for a minimum of 65 participants. After excluding 14 participants due to technical and data quality issues (described below), the final analyzed sample comprised 62 participants (39 female) aged $18-33$ years $\left(M_{\text {age }}=21.40, S D_{\text {age }}=3.55\right)$.

Procedures and design. Participants attended an information session on a Monday (Day 0) in which they completed a battery of trait measures, downloaded an ESM app (Instant Survey; Richardson, 2015) onto their smartphones, and were carefully instructed by the researcher on its use. Following recommendations for maximizing motivation and compliance in ESM studies (Conner \& Lehman, 2012), participants were encouraged to complete as many reports as possible, but were informed that accurate reports were more important than a perfect response rate, and that they could miss reports due to major inconveniences (e.g., driving, sleeping).

During the seven-day ESM component, which began the following day (Tuesday, Day 1), participants were prompted, via phone notifications and sound alerts, to complete a series of momentary reports. Each report comprised 24 items (completion time $\sim 2$ minutes), including questions on social context and state levels of extraversion, potential mediators, and PA, in a fixed order. Six reports were sent between 9am and 10pm each day at variable 60-150 minute intervals. The questionnaire became unavailable after 30 minutes following the initial alert. To encourage high completion rates, the researcher sent two text messages to 
update each participant on their overall response rates (usually Days 2 and 4), while thanking them and encouraging their continued effort.

Due to smartphone software incompatibility, eight participants were unable to complete the ESM component, and one participant revealed that he consistently responded inaccurately as his phone froze during reports. After excluding these data, the remaining 67 participants completed 1,934 out of 2,814 (68.73\%) possible reports; a typical response rate for ESM studies (Fleeson \& Gallagher, 2009). Of these, 23 reports comprising more than $85 \%$ identical responses (e.g., responding " 10 " for $\geq 20$ of the 23 Likert-type questions) were excluded. Finally, 5 participants who completed fewer than 15 valid reports were excluded, eliminating 62 reports. The final analyzed data comprised 62 participants who completed 1,849 out of $2,604(71 \%)$ possible reports $\left(M_{\text {reports }}=29.82, S D_{\text {reports }}=6.06\right)$.

The morning after the ESM component ended (Day 8), participants were emailed a link to a final survey comprising measures (unrelated to the stated hypotheses) about their previous week. All participants completed the online survey using their own computers or phones within 48 hours of completing the ESM component. Finally, participants read a debriefing statement and had the opportunity to discuss the study over the phone.

\section{Measures.}

Trait extraversion. Trait extraversion was assessed as in Studies 1 and 2.

Social context. Participants selected the mutually exclusive category that best described their situation in the past hour: alone, semi-social (with people but not interacting with them, e.g., in a lecture), or social (interacting with others).

State extraversion. Participants described their levels of extraverted behaviors in the previous hour ("In the past hour, how [talkative; bold; assertive; quiet; outgoing; reserved] were you?"; 0 = not at all, 10 = very). These six items were adapted from Goldberg's (1992) adjective markers; "quiet" and "reserved" were reverse-scored. 
State PA. Participants rated their current levels of PA ("How [lively; excited; enthusiastic] do you feel right now?"; $0=$ not at all, $10=$ extremely). These three items were drawn from Smillie, DeYoung, and Hall (2015).

State power. Participants rated their perceptions of influence over others in the past hour ("In the past hour, how much [power; influence] do you think you had over others?"; 0 $=$ none at all, $10=$ a great deal). These two items were adapted from previous state measures of social power (Anderson \& Kilduff, 2009; Langner \& Keltner, 2008).

State contribution. To capture participants' perceptions of their social value in the past hour, participants indicated their agreement $(0=$ disagree strongly, $10=$ agree strongly $)$ with three items adapted from the Flourishing Scale (Diener et al., 2010) and the Self-Worth subscale of the Comprehensive Inventory of Thriving (Su et al., 2014): "In the past hour, [what I was doing was valuable and worthwhile; the things I did were important for other people; I actively contributed to the happiness and wellbeing of others]".

Data Analyses. The resulting data had a multilevel structure, with reports (Level 1) nested within individuals (Level 2). As in Studies 1 and 2, descriptive statistics and correlations for Level 2 variables were computed using SPSS Version 23, whereas $\omega$ reliability coefficients for trait measures were computed using R. $\omega$ reliability coefficients for state measures, based on a multilevel confirmatory factor analysis framework (Bolger \& Laurenceau, 2013b; Geldhof, Preacher, \& Zyphur, 2014; Shrout \& Lane, 2012), were computed using Mplus Version 7 (Muthén \& Muthén, 1998-2012).

Mediation hypotheses were examined using a multilevel structural equation modeling (MSEM) framework (Bauer, Preacher, \& Gil, 2006; Muthén \& Asparouhov, 2011). Multilevel modeling was required as there was substantial between-person variance $(I C C(1) \mathrm{s}$ $>.14$; see Table 8 ). The effects of state extraversion on social contribution, power, and state PA were modeled as random slopes, as were the effects of social contribution and power on 
state PA. As extraverted behavior, social contribution, power, and PA were each assessed as momentary states, all MSEMs had a 1-1-1 structure. All state measures were centered around each individual's mean (i.e., aggregated states) to remove Level 2 variance from state variables. Multilevel analyses were then deployed using Mplus Version 7.4 (Muthén \& Muthén, 2012) with syntax adapted from Bolger and Laurenceau (2013c, p. 188).

Given that extraverted behaviors and perceived contribution and power would be expected to vary across social context, we statistically controlled for the fixed effect of social context in all multilevel models. Following Bolger and Laurenceau's (2013a) strong recommendation, all multilevel models also controlled for the fixed effect of the time elapsed since each individual's first ESM report. The resulting unstandardized $b$ coefficients quantify the average amount of change in the dependent variable associated with a one-unit change in the independent variable, independent of social situational and time course confounds.

\section{Results and Discussion}

Descriptive statistics. As usual, the trait extraversion measure $(M=3.36, S D=0.46)$ had good internal consistency $(\omega=.81)$. For state measures, Table 8 displays descriptive statistics, $\omega$ reliability estimates, and aggregate-level intercorrelations. The good $\omega$ coefficients $(\geq .82)$ for state measures indicate that they reliably assessed within-person change. The 1-ICC(1) statistics show that there was greater within-person variability than between-person variability for all measures. Participants reported roughly equal proportions of alone (30.8\%) and semi-social (30.4\%) situations, and slightly more social situations (38.8\%). Consistent with the extant literature, aggregate levels of extraverted states were positively correlated with aggregate levels of PA states (see Table 8). 
Table 8

Descriptive Statistics, Scale Reliabilities, and Intercorrelations Between Aggregate States

\begin{tabular}{lcccccccc}
\hline \multicolumn{1}{c}{ State Measure } & $M$ & $S D_{\mathrm{BP}}$ & $S D_{\mathrm{WP}}$ & $1-I C C(1)$ & 1 & 2 & 3 & 4 \\
\hline 1. Extraversion & 4.34 & 0.83 & 2.06 & .86 &. $\mathbf{9 3}$ & - & & \\
2. PA & 5.00 & 1.18 & 1.60 & .65 & .54 &. $\mathbf{8 4}$ & - & \\
3. Contribution & 4.75 & 0.98 & 1.84 & .78 & .62 & .60 & $\mathbf{. 8 2}$ & - \\
4. Power & 3.77 & 1.16 & 2.09 & .76 & .66 & .41 & .77 & $\mathbf{. 9 3}$
\end{tabular}

Note. Bold values denote $\omega$ reliability coefficients. $S D_{\mathrm{BP}}=$ between-person $S D ; S D_{\mathrm{WP}}=$ average within-person $S D$. 1-ICC(1) represents the proportion of total variation due to withinperson variation. All correlations are significant at $p<.01$.

Extraverted behaviors and PA states. As expected, individuals tended to report higher levels of PA in moments when they reported greater levels of extraverted behaviors, $b$ $=0.46, p<.001,95 \% \mathrm{CI}[0.40,0.52]$. The magnitude of this within-person relation varied significantly between persons, $S D=0.16, p<.001$. However, consistent with the findings of Study 2-and all previous studies in this literature - trait extraversion did not moderate the relation between extraverted behaviors and PA states, $b=-0.01, p=.606,95 \%$ CI $[-0.07$, 0.04]. In other words, extraverts and introverts both reported similar increases in PA when they acted relatively more extraverted in daily life.

Mediation models. Consistent with Hypotheses 1 and 2 and the results of our first two studies, social contribution $(\mathrm{PME}=24 \%)$ and power $(\mathrm{PME}=13 \%)$ both mediated the relation between extraverted behaviors and PA states in single-mediator models (see Table 9, Models 1 and 2). However, when entered together as simultaneous mediators (see Table 9, Model 3), social contribution continued to explain a significant $23 \%$ of this relation, but power no longer had a significant independent mediating effect (supporting Hypothesis 3). Finally, in contrast to Studies 1 and 2, the indirect effect via social contribution was significantly larger than the indirect effect via power. 
Table 9

Multilevel Mediation Models Tested in Study 3

\begin{tabular}{lccccc}
\hline \multicolumn{1}{c}{ Mediator } & $\begin{array}{c}\text { IV } \rightarrow \mathrm{M} \\
(a \text { path })\end{array}$ & $\begin{array}{c}\mathrm{M} \rightarrow \mathrm{DV} \\
(b \text { path })\end{array}$ & $\begin{array}{c}\text { Direct effect } \\
\left(c^{\prime} \text { path }\right)\end{array}$ & $\begin{array}{c}\text { Indirect effect } \\
(a \text { x } b \text { path })\end{array}$ & $\begin{array}{c}\text { 95\% CI of } \\
\text { indirect effect }\end{array}$ \\
\hline $\begin{array}{l}\text { Model 1 } \\
\text { Contribution }\end{array}$ & $0.54^{* * *}$ & $0.21^{* * *}$ & $0.35^{* * *}$ & $\mathbf{0 . 1 1}$ & {$[0.07,0.15]$} \\
$\begin{array}{l}\text { Model 2 } \\
\text { Power }\end{array}$ & $0.66^{* * *}$ & $0.11^{* * *}$ & $0.40^{* * *}$ & $\mathbf{0 . 0 6}$ & {$[0.02,0.09]$} \\
Model 3 & & & & & \\
Contribution & $0.54^{* * *}$ & $0.20^{* * *}$ & $0.34^{* * *}$ & $\mathbf{0 . 1 1}$ & {$[0.06,0.15]$} \\
Power & $0.66^{* * *}$ & 0.05 & & 0.02 & {$[-0.02,0.06]$} \\
Difference & & & $\mathbf{0 . 0 9}$ & {$[0.02,0.16]$} \\
\hline Note $* * p<.01, * * * p<001$. Indirect effects in bold denote that the $95 \%$ CI does not
\end{tabular}

capture zero.

\section{Summary}

As in Studies 1 and 2, social contribution and power mediated the relation between extraverted behavior and PA states as individual mediators, but social contribution was the only significant independent mediator when the two variables were entered simultaneously. In addition to conceptually replicating the pattern of findings demonstrated at the trait domain level (Study 1) and at the state level (Study 2), Study 3 also provided the first evidence that the indirect effect via contribution is significantly stronger than the indirect effect via power. These findings, combined with those of Studies 1 and 2, provide converging evidence that the relation between extraverted behavior and positive affect may stem from perceptions of beneficial social contributions more so than any kind of social influence. This evidence substantially clarifies the conceptual nature of the social contribution mediator first identified by Smillie, Wilt, and colleagues (2015). 
Study 3 also extends the state-level results of Study 2, as well as Smillie, Wilt, et al.'s (2015, Study 2) experimental study, in two ways. First, by sampling across a representative range of situations in participants' daily lives, our results suggest that the mediating effect of social contribution is not circumscribed to an artificial laboratory setting, but generalizes to everyday life. Second, assessing everyday experiences of perceived social value, rather than "contributions" to a trivial discussion task, offered a more faithful operationalization of Keyes' (1998) social contribution construct.

The key limitation of a naturalistic ESM paradigm is the lack of controlled manipulation of extraverted and proposed mediators, precluding inferences about causal direction. Though lagged analyses of temporally ordered variables can provide stronger tests of mediation (MacKinnon et al., 2007; Shrout \& Bolger, 2002), these were deemed inappropriate for this study, as lags were up to 3 hours apart, but the processes of interest are theoretically expected to vary rapidly (i.e., within minutes). Nevertheless, Study 3 complemented our experimental findings (Study 2) by conceptually replicating these results using ecologically valid methods.

\section{General Discussion}

Why are extraverts and extraverted moments happier? The present research aimed to clarify the recent finding that perceived social contributions help to explain why trait and state extraversion are associated with greater levels of PA (Smillie, Wilt, et al., 2015). We tested the mediating effects of social contribution and power, separately and simultaneously, to assess the extent to which these "contributions" comprised any kind of influence on others, relative to specifically positive influences. Across three studies, we consistently found that social contribution and power both mediated the relation between extraversion and PA in single-mediator models. When we tested their simultaneous mediating effects, however, all three studies revealed a significant indirect effect of extraversion on PA via social 
contribution, but not power. These findings held at the trait domain level (Study 1) and the state level (Studies 2 and 3), not only in the lab (Study 2) but also in everyday life (Study 3). Therefore, we conclude that perceptions of beneficial contributions - more than impact per se- - help to explain why extraverts and extraverted moments are happier.

\section{Clarifying the Social Contribution Effect}

The present studies continue to support the recent hypothesis that aspects of social experience, beyond quantity of social activity (e.g., Lucas et al., 2008), help to explain the relation between extraverted behaviors and PA (Smillie, Wilt, et al., 2015). This hypothesis was formed on the basis that extraverts report more positive social experiences (e.g., Wilson et al., 2015), in part due to their extraverted behaviors (Eaton \& Funder, 2003). In the present research, we focused on the mediating role of social impact processes, in hopes of clarifying the recent finding that perceptions of social contribution explained $70 \%$ of the effect of enacted extraversion on PA (Smillie, Wilt, et al., 2015). Given the ambiguous wording of Smillie, Wilt and colleagues' task-specific “percent contributed" measure, it was unclear whether the underlying process involved perceptions of influence, valuable contributions to a task, or beneficial contributions to other people.

Our results conceptually replicated, refined, and extended Smillie, Wilt, et al.'s (2015) social contribution finding in several ways. First, we employed improved measures of social contribution that aligned more closely with Keyes' (1998) conceptualization of social contribution as social value. Second, by testing the mediating effects of social contribution and power separately and concurrently, our findings demonstrated that the underlying process may more strongly involve perceptions of contributing positively, relative to a more general sense of influence (i.e., power). Finally, whereas Study 2 demonstrated these findings under similar conditions to Smillie, Wilt, and colleagues' experimental study, the ESM paradigm 
used in Study 3 extended these laboratory-based findings by showing that the mediating effect of social contribution generalizes to perceptions of social value in everyday life.

Although the difference in the significance of the two mediating effects occurred consistently across the three studies, only Study 3 found that the indirect effect via social contribution was significantly larger than the indirect effect via power. In addition, it is possible that we did not have sufficient statistical power to detect a small mediating effect of power when social contribution was in the same model. Nor do we claim that perceptions of general influence are irrelevant; indeed, we see social contribution as a particular manifestation of social power concerning perceptions of positive influence. The consistency of the pattern of findings across the three studies may suggest that the mediating effect of perceived positive contribution is stronger and more robust than the mediating effect of perceived general social influence.

As we only employed self-report measures of social contribution, multi-method measurement of this construct would further clarify the scope and interpretation of the social contribution effect. If the social consequences of personality can only be fully understood by including the perspectives of social partners (see Back \& Vazire, 2015), a crucial question is whether other people experience the purported positive impacts of the extraverted behaviors of those around them. As well as obtaining informant reports, future studies could code the conversational characteristics of social interactions recorded in the laboratory or in everyday life (see Mehl \& Robbins, 2012). For example, do those who are acting extraverted just talk more, or are their words actually more useful, relative to those who are acting introverted? Do conversational partners sound happier when a target is acting more extraverted? If not, then why do people perceive contributing in more valuable ways when acting extraverted? Strengths, Limitations, and Implications 
Although all three studies are statistically consistent with a mediating role of social contribution, we recognize the limits of statistical mediation. With no experimental manipulations, our cross-sectional (Study 1) and naturalistic ESM (Study 3) findings are causally ambiguous. Partially addressing this concern, the enacted extraversion paradigm employed in Study 2 provides somewhat stronger evidence for the causal effect of extraverted behavior on PA, social contribution, and power. Although we did not manipulate social contribution and power in Study 2, lagged analyses also suggested that T1 social contribution or power generally had downstream effects on T2 PA, over and above T1 PA. A second issue is that the indirect effect sizes in Studies 1 and 3 may be inflated by common method variance. However, the finding that self-rated social contribution mediated the relation between experimentally-manipulated extraverted behavior and informant-rated PA in Study 2 suggests that our key effect is not artifactual. Nevertheless, we recognize that it is surprisingly difficult to rigorously establish causal pathways (Bullock, Green, \& Ha, 2010), and see the current paper as a preliminary effort that lays the groundwork for the extensive program of research required to establish stronger evidence for causal mediation.

Despite these limitations, we find it compelling that our studies revealed highly consistent findings across three distinct methods with complementary strengths. Study 1 employed long-form measures of our key variables, assessed as global, enduring traits. Study 2 manipulated extraverted behavior under controlled laboratory conditions and obtained selfand informant ratings of extraverted behavior and state PA at two time points. Finally, the naturalistic ESM paradigm employed in Study 3 increased our confidence that the findings generalize to daily life. These methods enabled us to assess the social and affective correlates of trait extraversion (Study 1), as well as experimentally manipulated (Study 2) and everyday extraverted behavior (Study 3). Our three studies therefore provide a robust description of the 
relative strengths of associations and patterns of unique and shared variances between extraversion, social contribution, power, and PA, at the trait and state levels.

In this paper, we focused on clarifying the mediating effects of two social impact constructs. Recognizing this narrow scope, we wish to emphasize that social contribution and power did not completely explain the extraversion-PA relation in most of our models; rather, it is likely that multiple mechanisms underlie this association. Indeed, two studies published while this paper was under review found that daily relatedness mediated the relation between daily extraverted behavior and daily positive emotions (Howell et al., 2016) ${ }^{1}$, and that velocity (the perceived rate of progress toward a goal) mediated the relation between extraverted behavior and PA states (Wilt et al., 2016).

These two papers also provide new theoretical perspectives on the general mechanisms that may mediate the relation between personality states and PA states. Drawing from Self-Determination Theory (SDT; Ryan \& Deci, 2000), which posits that fulfilling autonomy, relatedness, and competence needs contributes to well-being, Howell and colleagues (2016) suggest that different personality states may satisfy these three needs to different extents. From this need satisfaction perspective, social contribution could help to satisfy the relatedness need, whereas rapid goal progress (Wilt et al., 2016) helps one to feel competent. Alternatively, Wilt and colleagues (2016) draw from control theories of selfregulation, which suggest that positive feelings result when a person is doing unexpectedly well (Carver, 2015; Carver \& Scheier, 1990). In contrast to SDT, control theories suggest that affective outcomes are linked to the rate of progress, not just goal attainment (or need satisfaction) per se. If goal velocity is a more general mechanism that links extraverted

\footnotetext{
${ }^{1}$ Although this was not the focus of the current paper, our ESM survey (Study 3) contained one relevant item, enabling us to conceptually replicate this recent finding (see Appendix).
} 
behavior with PA, social contribution, relatedness, and additional mediators could be conceptualized as goals that are more readily attained by enacting extraverted behaviors. This aligns with emerging frameworks which suggest that personality states are enacted to help accomplish specific goals (Fleeson \& Jayawickreme, 2015; McCabe \& Fleeson, 2012; McCabe \& Fleeson, 2016). Both frameworks allow for the possibility that several social and nonsocial mechanisms may help to account for the extraversion-PA relation (Smillie, 2013).

The notion that extraverted behavior can be construed as goal-directed action also suggests one way that the present findings could be integrated with the more established literature linking trait extraversion with neural processing of rewards (for a recent review, see Wacker \& Smillie, 2015). This literature shows that more extraverted individuals have more pronounced neural responses to reward (e.g., Cooper et al., 2014; Wu et al., 2014), attributed to dopaminergic signaling of motivationally salient stimuli (DeYoung, 2013; Pickering \& Pesola, 2014). These dopamine neurons are thought to be centrally involved in learning about and energizing and directing behavior toward rewarding outcomes. To the extent that such approach-motivated behaviors take the form of extraverted states, differential reward processing may explain why some people tend to engage in extraverted behavior more often than others (i.e., why the extraversion dimension exists). If extraverted behaviors trigger experiences such as enhanced perceptions of social contribution, and in turn, increased PA, and if these processes are repeated more frequently for those who are more reward-sensitive (i.e., extraverts), the processes that explain the relation between extraverted behavior and PA states could also help to explain the relation between trait extraversion and trait PA (Fleeson et al., 2002; Wilt et al., 2012). In this way, research on state-level mediators could uncover new explanations for the positive affectivity of trait extraverts.

Conceptually, for those who see PA as a core feature of extraversion (e.g., Watson \& Clark, 1997), the association between extraversion and PA may seem tautological. Others 
have shown that excluding affect-related items from measures of trait extraversion does not substantially influence its relation with measures of PA (Lucas \& Fujita, 2000; Smillie, DeYoung, \& Hall, 2015). However, by focusing on states, we examined the complementary question of why the affective and behavioral components of extraversion cohere. This approach is in line with the emerging focus in personality research on the dynamic links among various affective, behavioral, and cognitive states (e.g., Howell et al., 2016; Smillie, Wilt, et al., 2015; Wilt et al., 2016). From this perspective, our results suggest that social cognitions - specifically, perceptions of social contribution - may help to bind the affective and behavioral components of extraversion.

Finally, concerning practical implications, our findings may point to personalityinformed pathways for increasing subjective well-being. Several researchers have suggested that acting extraverted could be an effective intervention for increasing an individual's levels of PA (e.g., Blackie, Roepke, Forgeard, Jayawickreme, \& Fleeson, 2014). Although introverts do not appear to find it distressing, effortful, or inauthentic to act extraverted in the short-term (e.g., Fleeson \& Wilt, 2010; Gallagher et al., 2011; McNiel et al., 2010; Zelenski et al., 2012), extraverted behavior may be related to delayed fatigue for introverts and extraverts alike (Leikas \& Juhani-Ilmarinen, 2016). There may also be other reasons why introverts may be reluctant to act extraverted to increase their PA. For example, introverts may underpredict how enjoyable acting extraverted can be (Zelenski et al., 2013), and an emerging cultural movement aims to celebrate introverts "for who they are" (Cain, 2012; http://www.quietrev.com). Given these considerations, mediational investigations could offer an alternative approach to increasing PA: targeting the processes that mediate the relation between extraverted behaviors and PA states. For example, if the link between perceived social contribution and PA is found to be causal, and if there are several non-extraverted ways to enhance these perceptions (e.g., Aknin, Dunn, Whillans, Grant, \& Norton, 2013), this 
could potentially empower introverted individuals with additional pathways for increasing their PA in ways that best align with their preferences (Lyubomirsky \& Layous, 2013).

\section{Conclusion}

The present research shows that perceptions of social contribution, more so than a general sense of impact, independently explain why extraverts and extraverted moments are happier. These findings continue to support the hypothesis that qualitative aspects of social experience help to explain the relations that trait extraversion and extraverted behavior have with PA (Smillie, Wilt, et al., 2015). By describing the social experiences that covary with PA, this research also points to additional pathways for increasing subjective well-being, beyond acting extraverted. Before any translational implications can be realized, however, these links need to be causally established and replicated by future experimental investigations. Such endeavors, informed by personality theories, hold the potential of revealing the mutable processes that can enhance well-being in all individuals. 


\section{Acknowledgements}

This research was supported by funding from the Melbourne Research Grant Support Scheme, awarded to the last author. 


\section{References}

Aknin, L. B., Dunn, E. W., Whillans, A. V, Grant, A. M., \& Norton, M. I. (2013). Making a difference matters: Impact unlocks the emotional benefits of prosocial spending. Journal of Economic Behavior \& Organization, 88, 90-95. http://dx.doi.org/10.1016/j.jebo.2013.01.008

Anderson, C., \& Berdahl, J. L. (2002). The experience of power: Examining the effects of power on approach and inhibition tendencies. Journal of Personality and Social Psychology, 83(6), 1362-1377. http://dx.doi.org/10.1037/0022-3514.83.6.1362

Anderson, C., John, O. P., \& Keltner, D. (2012). The personal sense of power. Journal of Personality, 80(2), 313-344. http://dx.doi.org/10.1111/j.1467-6494.2011.00734.x

Anderson, C., \& Kilduff, G. J. (2009). Why do dominant personalities attain influence in face-to-face groups? The competence-signaling effects of trait dominance. Journal of Personality and Social Psychology, 96(2), 491-503. http://dx.doi.org/10.1037/a0014201

Anderson, C., Spataro, S. E., \& Flynn, F. J. (2008). Personality and organizational culture as determinants of influence. The Journal of Applied Psychology, 93(3), 702-710. http://dx.doi.org/10.1037/0021-9010.93.3.702

Back, M. D., \& Vazire, S. (2015). The social consequences of personality: Six suggestions for future research. European Journal of Personality, 29(2), 296-307. http://dx.doi.org/10.1002/per.1998

Bauer, D. J., Preacher, K. J., \& Gil, K. M. (2006). Conceptualizing and testing random indirect effects and moderated mediation in multilevel models: New procedures and recommendations. Psychological Methods, 11(2), 142-163. http://dx.doi.org/10.1037/1082-989X.11.2.142

Berdahl, J. L., \& Martorana, P. (2006). Effects of power on emotion and expression during a 
controversial group discussion. European Journal of Social Psychology, 36(4), 497-509. http://dx.doi.org/10.1002/ejsp.354

Berry, D. S., Willingham, J. K., \& Thayer, C. A. (2000). Affect and personality as predictors of conflict and closeness in young adults' friendships. Journal of Research in Personality, 34(1), 84-107. http://dx.doi.org/10.1006/jrpe.1999.2271

Blackie, L. E. R., Roepke, A. M., Forgeard, M. J. C., Jayawickreme, E., \& Fleeson, W. (2014). Act well to be well: The promise of changing personality states to promote wellbeing. In A. C. Parks \& S. Schueller (Eds.), The Wiley-Blackwell handbook of positive psychological interventions (pp. 462-474). Somerset: Wiley-Blackwell.

Bolger, N., \& Laurenceau, J.-P. (2013a). Fundamentals of intensive longitudinal data. In N. Bolger \& J.-P. Laurenceau (Eds.), Intensive longitudinal methods: An introduction to diary and experience sampling research (pp. 27-39). New York: Guilford Press.

Bolger, N., \& Laurenceau, J.-P. (2013b). Psychometrics of intensive longitudinal measures of emotional states. In N. Bolger \& J.-P. Laurenceau (Eds.), Intensive longitudinal methods: An introduction to diary and experience sampling research (pp. 127-142). New York: Guilford Press.

Bolger, N., \& Laurenceau, J.-P. (2013c). Within-subject mediation analysis. In N. Bolger \& J.-P. Laurenceau (Eds.), Intensive longitudinal methods: An introduction to diary and experience sampling research (pp. 177-195). New York: Guilford Press.

Bolger, N., Stadler, G., \& Laurenceau, J.-P. (2012). Power analysis for intensive longitudinal studies. In M. R. Mehl \& T. S. Conner (Eds.), Handbook of research methods for studying daily life (pp. 285- 301). New York: Guilford.

Buhrmester, M., Kwang, T., \& Gosling, S. D. (2011). Amazon's Mechanical Turk: A new source of inexpensive, yet high-quality, data? Perspectives on Psychological Science, 
6(1), 3-5. http://dx.doi.org/10.1177/1745691610393980

Bullock, J. G., Green, D. P., \& Ha, S. E. (2010). Yes, but what's the mechanism? (Don't expect an easy answer). Journal of Personality and Social Psychology, 98(4), 550-558. http://dx.doi.org/10.1037/a0018933

Cain, S. (2012). Quiet: The power of introverts in a world that can't stop talking. New York: Crown Publishers.

Cantor, N. (1990). From thought to behavior: "Having" and "doing" in the study of personality and cognition. American Psychologist, 45(6), 735-750. http://dx.doi.org/10.1037/0003-066X.45.6.735

Carver, C. S. (2015). Control processes, priority management, and affective dynamics. Emotion Review, 7(4), 301-307. http://dx.doi.org/10.1177/1754073915590616

Carver, C. S., \& Scheier, M. F. (1990). Origins and functions of positive and negative affect: A control-process view. Psychological Review, 97(1), 19-35. http://dx.doi.org/10.1037/0033-295X.97.1.19

Ching, C. M., Church, A. T., Katigbak, M. S., Reyes, J. A. S., Tanaka-Matsumi, J., Takaoka, S., ... Ortiz, F. A. (2014). The manifestation of traits in everyday behavior and affect: A five-culture study. Journal of Research in Personality, 48, 1-16. http://dx.doi.org/10.1016/j.jrp.2013.10.002

Cicchetti, D. V. (1994). Guidelines, criteria, and rules of thumb for evaluating normed and standardized assessment instruments in psychology. Psychological Assessment, 6(4), 284-290. http://dx.doi.org/10.1037/1040-3590.6.4.284

Cohen, J. (1992). A power primer. Psychological Bulletin, 112(1), 155-159. http://dx.doi.org/10.1037/0033-2909.112.1.155

Conner, T. S., \& Lehman, B. (2012). Getting started: Launching a study in daily life. In M. R. 
Mehl \& T. S. Conner (Eds.), Handbook of research methods for studying daily life (pp. 89-107). New York: Guilford Press.

Cooper, A. J., Duke, E., Pickering, A. D., \& Smillie, L. D. (2014). Individual differences in reward prediction error: Contrasting relations between feedback-related negativity and trait measures of reward sensitivity, impulsivity and extraversion. Frontiers in Human Neuroscience, 8, 248. http://dx.doi.org/10.3389/fnhum.2014.00248

DeYoung, C. G. (2013). The neuromodulator of exploration: A unifying theory of the role of dopamine in personality. Frontiers in Human Neuroscience, 7, 762. http://dx.doi.org/10.3389/fnhum.2013.00762

DeYoung, C. G., Quilty, L. C., \& Peterson, J. B. (2007). Between facets and domains: 10 aspects of the Big Five. Journal of Personality and Social Psychology, 93(5), 880-96. http://dx.doi.org/10.1037/0022-3514.93.5.880

Diener, E., Wirtz, D., Tov, W., Kim-Prieto, C., Choi, D., Oishi, S., \& Biswas-Diener, R. (2010). New well-being measures: Short scales to assess flourishing and positive and negative feelings. Social Indicators Research, 97(2), 143-156. http://dx.doi.org/10.1007/s11205-009-9493-y

Dunn, T. J., Baguley, T., \& Brunsden, V. (2014). From alpha to omega: A practical solution to the pervasive problem of internal consistency estimation. British Journal of Psychology, 105(3), 399-412. http://dx.doi.org/10.1111/bjop.12046

Eaton, L. G., \& Funder, D. C. (2003). The creation and consequences of the social world: An interactional analysis of extraversion. European Journal of Personality, 17(5), 375-395. http://dx.doi.org/10.1002/per.477

Faul, F., Erdfelder, E., Lang, A.-G., \& Buchner, A. (2007). G*Power 3: A flexible statistical power analysis program for the social, behavioral, and biomedical sciences. Behavior 
Research Methods, 39(2), 175-191. http://dx.doi.org/10.3758/BF03193146

Festa, C. C., McNamara Barry, C., Sherman, M. F., \& Grover, R. L. (2012). Quality of college students' same-sex friendships as a function of personality and interpersonal competence. Psychological Reports, 110(1), 283-296.

http://dx.doi.org/10.2466/04.09.10.21.PR0.110.1.283-296

Fleeson, W., \& Gallagher, P. (2009). The implications of Big Five standing for the distribution of trait manifestation in behavior: Fifteen experience-sampling studies and a meta-analysis. Journal of Personality and Social Psychology, 97(6), 1097-1114. http://dx.doi.org/10.1037/a0016786

Fleeson, W., \& Jayawickreme, E. (2015). Whole trait theory. Journal of Research in Personality, 56, 82-92. http://dx.doi.org/10.1016/j.jrp.2014.10.009

Fleeson, W., \& Wilt, J. (2010). The relevance of Big Five trait content in behavior to subjective authenticity: Do high levels of within-person behavioral variability undermine or enable authenticity achievement? Journal of Personality, 78(4), 13531382. http://dx.doi.org/10.1111/j.1467-6494.2010.00653.x

Fleeson, W., Malanos, A. B., \& Achille, N. M. (2002). An intraindividual process approach to the relationship between extraversion and positive affect: Is acting extraverted as "good" as being extraverted? Journal of Personality and Social Psychology, 83(6), 1409-1422. http://dx.doi.org/10.1037/0022-3514.83.6.1409

Fritz, M. S., \& MacKinnon, D. P. (2007). Required sample size to detect the mediated effect. Psychological Science, 18(3), 233-239. http://dx.doi.org/10.1111/j.14679280.2007.01882.x

Gallagher, P., Fleeson, W., \& Hoyle, R. H. (2011). A self-regulatory mechanism for personality trait stability: Contra-trait effort. Social Psychological and Personality 
Science, 2(4), 335-342. http://dx.doi.org/10.1177/1948550610390701

Geldhof, G. J., Preacher, K. J., \& Zyphur, M. J. (2014). Reliability estimation in a multilevel confirmatory factor analysis framework. Psychological Methods, 19(1), 72-91. http://dx.doi.org/10.1037/a0032138

Goldberg, L. R. (1992). The development of markers for the Big-Five factor structure. Psychological Assessment. http://dx.doi.org/10.1037/1040-3590.4.1.26

Gross, J. J., Sutton, S. K., \& Ketelaar, T. (1998). Relations between affect and personality: Support for the affect-level and affective reactivity views. Personality and Social Psychology Bulletin, 24(3), 279-288. http://dx.doi.org/10.1177/0146167298243005

Hayes, A. F. (2013). Introduction to mediation, moderation, and conditional process analysis: A regression-based approach. New York: Guilford Press.

Hayes, A. F. (2014). PROCESS (Version 2.13) [SPSS macro]. Retrieved from http://www.processmacro.org/download.html

Howell, R. T., Ksendzova, M., Nestingen, E., Yerahian, C., \& Iyer, R. (2016). Your personality on a good day: How trait and state personality predict daily well-being. Journal of Research in Personality. Advance online publication. http://dx.doi.org/10.1016/j.jrp.2016.08.001

John, O. P., Naumann, L. P., \& Soto, C. J. (2008). Paradigm shift to the integrative Big five trait taxonomy: History, measurement, and conceptual issues. In O. P. John, R. W. Robins, \& L. A. Pervin (Eds.), Handbook of personality: Theory and research (3rd ed., pp. 114-158). New York: Guilford Press.

Kelley, K., \& Lai, K. (2012). MBESS (Version 3.3.3) [R package]. Retrieved from https://cran.r-project.org/web/packages/MBESS/index.html

Keltner, D., Gruenfeld, D., Galinsky, A., \& Kraus, M. W. (2010). Paradoxes of power: 
Dynamics of the acquisition, experience, and social regulation of social power. In A. Guinote \& T. K. Vescio (Eds.), The social psychology of power (pp. 177-208). New York: The Guilford Press.

Keltner, D., Gruenfeld, D. H., \& Anderson, C. (2003). Power, approach, and inhibition. Psychological Review, 110(2), 265-284. http://dx.doi.org/10.1037/0033-295X.110.2.265

Keyes, C. L. M. (1998). Social well-being. Social Psychology Quarterly, 61(2), 121-140. http://dx.doi.org/10.2307/2787065

Kreft, G., \& de Leeuw, J. (1998). Introducing multilevel modeling. Thousand Oaks, CA: Sage.

Langner, C. A., \& Keltner, D. (2008). Social power and emotional experience: Actor and partner effects within dyadic interactions. Journal of Experimental Social Psychology, 44(3), 848-856. http://dx.doi.org/10.1016/j.jesp.2007.08.002

Larsen, R. J., \& Ketelaar, T. (1989). Extraversion, neuroticism and susceptibility to positive and negative mood induction procedures. Personality and Individual Differences, 10(12), 1221-1228. http://dx.doi.org/10.1016/0191-8869(89)90233-X

Leikas, S., \& Ilmarinen, V. J. (2016). Happy now, tired later? Extraverted and Conscientious behavior are related to immediate mood gains, but to later fatigue. Journal of Personality. Advance online publication. http://dx.doi.org/10.1111/jopy.12264

Lucas, R. E., Diener, E., Grob, A., Suh, E. M., \& Shao, L. (2000). Cross-cultural evidence for the fundamental features of extraversion. Journal of Personality and Social Psychology, 79(3), 452-468. http://dx.doi.org/10.1037//0022-3514.79.3.452

Lucas, R. E., \& Fujita, F. (2000). Factors influencing the relation between extraversion and pleasant affect. Journal of Personality and Social Psychology, 79(6), 1039-1056. http://dx.doi.org/10.1037/0022-3514.79.6.1039 
Lucas, R. E., Le, K., \& Dyrenforth, P. S. (2008). Explaining the extraversion/positive affect relation: Sociability cannot account for extraverts' greater happiness. Journal of Personality, 76(3), 385-414. http://dx.doi.org/10.1111/j.1467-6494.2008.00490.x

Lyubomirsky, S., \& Layous, K. (2013). How do simple positive activities increase wellbeing? Current Directions in Psychological Science, 22(1), 57-62. http://dx.doi.org/10.1177/0963721412469809

Maas, C. J., \& Hox, J. (2005). Sufficient sample sizes for multilevel modeling. Journal of Research Methods for the Behavioral and Social Sciences, 1(3), 86-92. http://dx.doi.org/10.1027/1614-1881.1.3.86

McCabe, K. O., \& Fleeson, W. (2012). What is extraversion for? Integrating trait and motivational perspectives and identifying the purpose of extraversion. Psychological Science, 23(12), 1498-1505. http://dx.doi.org/10.1177/0956797612444904

Mccabe, K. O., \& Fleeson, W. (2016). Are traits useful? Explaining trait manifestations as tools in the pursuit of goals. Journal of Personality and Social Psychology, 110(2), 287301. http://dx.doi.org/10.1037/a0039490

McDonald, R. P. (1999). Test theory: A unified treatment. Mahwah, N. J.: L. Erlbaum Associates.

McLean, K. C., \& Pasupathi, M. (2006). Collaborative narration of the past and extraversion. Journal of Research in Personality, 40(6), 1219-1231. http://dx.doi.org/10.1016/j.jrp.2005.11.006

McNiel, J. M., \& Fleeson, W. (2006). The causal effects of extraversion on positive affect and neuroticism on negative affect: Manipulating state extraversion and state neuroticism in an experimental approach. Journal of Research in Personality, 40(5), 529-550. http://dx.doi.org/10.1016/j.jrp.2005.05.003 
McNiel, J. M., Lowman, J. C., \& Fleeson, W. (2010). The effect of state extraversion on four types of affect. European Journal of Personality, 24(1), 18-35. http://dx.doi.org/10.1002/per.738

Mehl, M. R., \& Robbins, M. L. (2012). Naturalistic observation sampling: The electronically activated recorder (EAR). In M. R. Mehl \& T. S. Conner (Eds.), Handbook of research methods for studying daily life (pp. 176-192). New York: Guilford Press.

Muthén, B. O., \& Asparouhov, T. (2011). Beyond multilevel regression modeling: Multilevel analysis in a general latent variable framework. In J. Hox \& J. K. Roberts (Eds.), The handbook of advanced multilevel analysis (pp. 15-40). New York: Taylor \& Francis.

Muthén, L., \& Muthén, B. (2012). Mplus user's guide (7th ed.). Los Angeles, CA: Muthén \& Muthén.

Okumura, Y. (2012). rpsychi (Version 0.8) [R package]. Retrieved from https://cran.rproject.org/web/packages/rpsychi/index.html

Pickering, A. D., \& Pesola, F. (2014). Modeling dopaminergic and other processes involved in learning from reward prediction error: Contributions from an individual differences perspective. Frontiers in Human Neuroscience, 8, 740.

http://dx.doi.org/10.3389/fnhum.2014.00740

Podsakoff, P. M., MacKenzie, S. B., Lee, J.-Y., \& Podsakoff, N. P. (2003). Common method biases in behavioral research: A critical review of the literature and recommended remedies. The Journal of Applied Psychology, 88(5), 879-903. http://dx.doi.org/10.1037/0021-9010.88.5.879

Preacher, K. J., \& Hayes, A. F. (2008). Asymptotic and resampling strategies for assessing and comparing indirect effects in multiple mediator models. Behavior Research Methods, 40(3), 879-891. http://dx.doi.org/10.3758/BRM.40.3.879 
Preacher, K. J., \& Kelley, K. (2011). Effect size measures for mediation models: Quantitative strategies for communicating indirect effects. Psychological Methods, 16(2), 93-115. http://dx.doi.org/10.1037/a0022658

R Core Team. (2016). R: A language and environment for statistical computing. $\mathrm{R}$ Foundation for Statistical Computing, Vienna, Austria. Retrieved from http:/www.Rproject.org

Richardson, B. (2015). Instant Survey (iOS Version 1.3; Android Version 1.1) [Mobile application software]. Retrieved from https://itunes.apple.com/us/app/instantsurvey/id955226674? $\mathrm{mt}=8$ or https://play.google.com/store/apps/details?id=au.edu.deakin.psychology.surveyframewo rk

Rosenberg, E. L. (1998). Levels of analysis and the organization of affect. Review of General Psychology, 2(3), 247-270. http://dx.doi.org/10.1037//1089-2680.2.3.247

Ryan, R. M., \& Deci, E. L. (2000). Self-determination theory and the facilitation of intrinsic motivation, social development, and well-being. The American Psychologist, 55(1), 6878. http://dx.doi.org/10.1037/0003-066X.55.1.68

Shrout, P. E., \& Bolger, N. (2002). Mediation in experimental and nonexperimental studies: New procedures and recommendations. Psychological Methods, 7(4), 422. http://dx.doi.org/10.1037//1082-989x.7.4.422

Shrout, P. E., \& Fleiss, J. L. (1979). Intraclass correlations: Uses in assessing rater reliability. Psychological Bulletin, 86(2), 420-428. http://dx.doi.org/10.1037/0033-2909.86.2.420

Shrout, P. E., \& Lane, S. P. (2012). Psychometrics. In M. R. Mehl \& T. S. Conner (Eds.), Handbook of research methods for studying daily life (pp. 302-320). New York: Guilford Press. 
Smillie, L. D. (2013). Why does it feel good to act like an extravert? Social and Personality Psychology Compass, 7(12), 878-887. http://dx.doi.org/10.1111/spc3.12077

Smillie, L. D., DeYoung, C. G., \& Hall, P. J. (2015). Clarifying the relation between extraversion and positive affect. Journal of Personality, 83(5), 564-574. http://dx.doi.org/10.1111/jopy.12138

Smillie, L. D., Wilt, J., Kabbani, R., Garratt, C., \& Revelle, W. (2015). Quality of social experience explains the relation between extraversion and positive affect. Emotion, 15(3), 339-49. http://dx.doi.org/10.1037/emo0000047

Steel, P., Schmidt, J., \& Shultz, J. (2008). Refining the relationship between personality and subjective well-being. Psychological Bulletin, 134(1), 138-161. http://dx.doi.org/10.1037/0033-2909.134.1.138

Su, R., Tay, L., \& Diener, E. (2014). The development and validation of the Comprehensive Inventory of Thriving (CIT) and the Brief Inventory of Thriving (BIT). Applied Psychology: Health and Well-Being, 6(3), 251-279. http://dx.doi.org/10.1111/aphw.12027

Watson, D., \& Clark, L. A. (1997). Extraversion and its positive emotional core. In R. Hogan, J. Johnson, \& S. Briggs (Eds.), Handbook of personality psychology (pp. 767-793).

Watson, D., Clark, L. A., \& Tellegen, A. (1988). Development and validation of brief measures of positive and negative affect: The PANAS scales. Journal of Personality and Social Psychology, 54(6), 1063-1070. http://dx.doi.org/10.1037/0022-3514.54.6.1063

Watson, D., \& Tellegen, A. (1985). Toward a consensual structure of mood. Psychological Bulletin, 98(2), 219-35. http://dx.doi.org/10.1037/0033-2909.98.2.219

Wilson, R. E., Harris, K., \& Vazire, S. (2015). Personality and friendship satisfaction in daily life: Do everyday social interactions account for individual differences in friendship 
satisfaction? European Journal of Personality, 29(2), 173-186.

http://dx.doi.org/10.1002/per.1996

Wilt, J. A., Bleidorn, W., \& Revelle, W. (2016). Velocity explains the links between personality states and affect. Journal of Research in Personality. Advance online publication. http://dx.doi.org/10.1016/j.jrp.2016.06.008

Wilt, J., Noftle, E. E., Fleeson, W., \& Spain, J. S. (2012). The dynamic role of personality states in mediating the relationship between extraversion and positive affect. Journal of Personality, 80(5), 1205-1236. http://dx.doi.org/10.1111/j.1467-6494.2011.00756.x

Wu, C. C., Samanez-Larkin, G. R., Katovich, K., \& Knutson, B. (2014). Affective traits link to reliable neural markers of incentive anticipation. NeuroImage, 84, 279-289. http://dx.doi.org/10.1016/j.neuroimage.2013.08.055

Zelenski, J. M., Santoro, M. S., \& Whelan, D. C. (2012). Would introverts be better off if they acted more like extraverts? Exploring emotional and cognitive consequences of counterdispositional behavior. Emotion, 12(2), 290-303.

http://dx.doi.org/10.1037/a0025169

Zelenski, J. M., Whelan, D. C., Nealis, L. J., Besner, C. M., Santoro, M. S., \& Wynn, J. E. (2013). Personality and affective forecasting: Trait introverts underpredict the hedonic benefits of acting extraverted. Journal of Personality and Social Psychology, 104(6), 1092-1108. http://dx.doi.org/10.1037/a0032281 
Appendix

\section{Supplemental Analyses}

While the present paper was under review, Howell and colleagues (2016) presented new daily diary data supporting relatedness (feelings of closeness and connectedness) as a mediator of the relation between daily extraverted behavior and daily PA states. Although this was not the focus of our paper, our ESM survey (Study 3) included one item that measured perceived closeness ("In the past hour, how close did you feel to other people?"; 0

$=$ not at all, $10=$ extremely close $\left.M=5.12, S D_{\mathrm{BP}}=1.37, S D_{\mathrm{WP}}=2.17,1-I C C(1)=0.72\right)$. This enabled us to examine whether Howell and colleagues' finding would replicate at the state (rather than daily) level, and to compare the mediating effects of relatedness with social contribution.

As shown in Table A1, we replicate Howell and colleagues' (2016) finding: perceived relatedness mediated $28 \%$ of the relation between extraverted behavior and state PA (see Table A1, Model 4). At the aggregate state level, contribution and relatedness were highly correlated, $r=.81, p<.001$. Despite this, a multiple-mediator model revealed that social contribution $(\mathrm{PME}=15 \%)$ and relatedness $(\mathrm{PME}=24 \%)$ independently mediated the relation between extraverted behavior and PA (see Table A1, Model 2), and that this model explained $16 \%$ more of this association, relative to the model with only social contribution as a mediator (see Table 9, Model 1). The magnitudes of these indirect effects were not significantly different, $b=-0.04,95 \%$ CI $[-0.08,0.01]$. This suggests that there are likely to be multiple mechanisms that explain the link between extraverted behavior and PA. 
Table A1

Additional Multilevel Mediation Models for Study 3

\begin{tabular}{lccccc}
\hline \multicolumn{1}{c}{ Mediator } & $\begin{array}{c}\text { IV } \rightarrow \mathrm{M} \\
(a \text { path })\end{array}$ & $\begin{array}{c}\mathrm{M} \rightarrow \mathrm{DV} \\
(b \text { path })\end{array}$ & $\begin{array}{c}\text { Direct effect } \\
\left(c^{\prime} \text { path }\right)\end{array}$ & $\begin{array}{c}\text { Indirect effect } \\
(a \text { x } b \text { path })\end{array}$ & $\begin{array}{c}95 \% \text { CI of } \\
\text { indirect effect }\end{array}$ \\
\hline Model 4 & & & & & \\
Relatedness & $0.59^{* * *}$ & $0.23^{* * *}$ & $0.33^{* * *}$ & $\mathbf{0 . 1 3}$ & {$[0.09,0.17]$} \\
Model 5 & & & & & \\
Contribution & $0.54^{* * *}$ & $0.14^{* * *}$ & $0.28^{* * *}$ & $\mathbf{0 . 0 7}$ & {$[0.04,0.10]$} \\
Relatedness & $0.59^{* * *}$ & $0.19^{* * *}$ & & $\mathbf{0 . 1 1}$ & {$[0.07,0.15]$} \\
Difference & & & & -0.04 & {$[-0.08,0.01]$} \\
\hline
\end{tabular}

Note. ${ }^{* *} p<.01, * * * p<.001$. Indirect effects in bold denote that the $95 \%$ CI does not capture zero. 